\title{
Ioannis Metaxás et le religieux (1936-1941) : expérience historique et débats actuels en Grèce
}

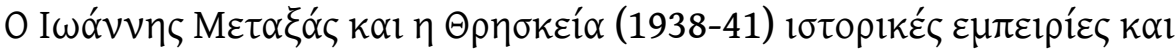

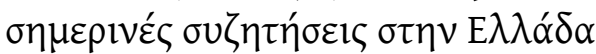

Ioannis Metaxas and Religion (1938-41): Historical Experience and Current Debates in Greece

Isabelle Dépret

\section{OpenEdition}

\section{Journals}

Electronic version

URL: https://journals.openedition.org/ceb/5120

DOI: $10.4000 /$ ceb. 5120

ISSN: 2261-4184

\section{Publisher}

INALCO

\section{Electronic reference}

Isabelle Dépret, "Ioannis Metaxás et le religieux (1936-1941) : expérience historique et débats actuels en Grèce", Cahiers balkaniques [Online], 42 | 2014, Online since 05 June 2014, connection on 07 July 2021. URL: http://journals.openedition.org/ceb/5120 ; DOI: https://doi.org/10.4000/ceb.5120

This text was automatically generated on 7 July 2021.

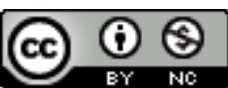

Cahiers balkaniques est mis à disposition selon les termes de la Licence Creative Commons Attribution - Pas d'Utilisation Commerciale 4.0 International. 


\title{
Ioannis Metaxás et le religieux (1936-1941) : expérience historique et débats actuels en Grèce
}

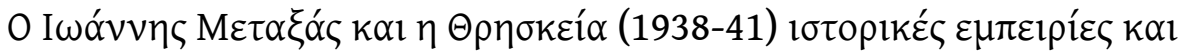

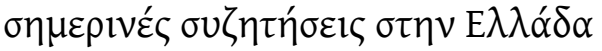 \\ Ioannis Metaxas and Religion (1938-41): Historical Experience and Current \\ Debates in Greece
}

Isabelle Dépret

\section{Introduction}

1 Le régime instauré, en Grèce, par Ioannis Metaxás du 4 août 1936 au 29 janvier 1941 témoigne de la radicalisation autoritaire, militaire, anticommuniste de l'Europe durant les années 1930. Après 1974 - et la chute des Colonels - le régime metaxiste a été répudié comme antithèse parfaite de la République parlementaire, démocratique, respectueuse des droits de l'homme et de la liberté d'expression à laquelle ce pays a choisi de s'identifier. Pour autant, dans la Grèce actuelle, la figure du général Metaxás jouit d'une image bien plus ambivalente : rejeté comme dictateur, comme symbole du poids longtemps marquant de l'armée dans la vie politique, l'homme du 4 août est parallèlement respecté, voire honoré en tant qu'auteur du « Non » décisif à l'ultimatum italien, le 28 octobre $1940^{1}$, stratège brillant et « héros » de la campagne d'Albanie à l'automne $1940^{2}$.

Depuis la fin des années 2000, dans un pays tourmenté par une grave crise financière, par le recul de l'État social, le régime metaxiste tend à être réexaminé ${ }^{3}$. Sont alors parfois soulignées les importantes mesures sociales adoptées de 1936 à 1941 : mise en place d'un salaire minimum, d'un congé de maternité, d'une assurance chômage et plus généralement d'un système de sécurité sociale; réduction du temps de travail à 40 heures; octroi de congés payés ; remise de dettes pour les agriculteurs et garantie de 
prix minimum pour les produits agricoles. Sont aussi pointées la progression du revenu national et de la production industrielle à la fin des années 1930, la stabilisation de la monnaie, la réalisation d'un vaste programme de travaux publics, la construction d'infrastructures (télécommunications, chemins de fer, routes, drainage), la baisse du chômage durant les premières années du régime. Au regard de l'appauvrissement et des incertitudes présentes, est parfois aussi mise en relief l'aptitude de ce régime à renforcer la discipline sociale, à combattre l'insécurité, les intrigues et la corruption politiciennes ${ }^{4}$.

3 Pour la plupart des historiens, ce régime serait plus proche du système autoritaire, paternaliste et conservateur du Portugal salazariste ou de l'Espagne franquiste qu'à strictement parler du fascisme italien ${ }^{5}$ ou du nazisme. Selon la thèse établie, le régime du 4 août se distinguerait sur trois points clés de ces deux derniers régimes : d'une part, Metaxás ne serait jamais parvenu à constituer un mouvement ou un grand parti politique de masse; ce régime aurait davantage poursuivi une politique extérieure défensive, par opposition aux projets expansionnistes d'Adolphe Hitler ou de Benito Mussolini ; enfin, Métaxas n'aurait pas mis en œuvre de politique antisémite ${ }^{6}$.

Si nombre de travaux ont examiné la politique extérieure de ce gouvernement ${ }^{7}$, l'idéologie et l'iconographie du pouvoir, la personnalité de Metaxás ou encore l'Organisation nationale de la Jeunesse (EON), la question religieuse est restée assez peu défrichée. Nous envisagerons donc les possibles spécificités du régime metaxiste à cet égard. Ces éléments éclairent les débats - toujours actuels - autour d'un moment sensible du passé national.

\section{La religion, pilier du régime metaxiste : majorité religieuse et unité nationale}

\section{loannis Metaxás, un militaire croyant}

\section{Un militaire brillant}

5 Ioannis Metaxás est issu d'une famille aisée de hauts fonctionnaires et d'hommes politiques $^{8}$, famille au passé aristocratique. Dans son journal, Metaxás écrit en 1901 qu'il se considère comme « un membre de l'aristocratie ayant de longue date combattu pour le roi et l'État $"$ '.

6 Il est né en 1871 sur l'île d'Ithaque, dans l'archipel des îles ioniennes cédées quelques années plus tôt par la Grande-Bretagne à l'État grec. La famille Metaxás, anoblie en 1691 sous administration vénitienne, perd tout titre nobiliaire en 1864, lorsque l'État grec annexe la région et perd l'essentiel de sa fortune à la fin du XIX ${ }^{\mathrm{e}}$ siècle ${ }^{10}$.

7 Il s'oriente tôt vers une carrière militaire. Après des études brillantes à la prestigieuse Académie militaire d'Evelpides de 1885 à 1890, il entre en 1897 au ministère de la Guerre grâce à l'appui d'un membre de sa famille, alors ministre. Il participe à la guerre gréco-ottomane de 1897, expédition durant laquelle il noue des liens très positifs avec le futur roi Constantin, commandant en chef de l'armée hellénique ${ }^{11}$. Cette période cristallise son mépris du monde politique et parlementaire, mépris qui ne fera que s'accroître après $1923^{12}$.

De 1899 à 1903, il poursuit des études à l'Académie militaire de Berlin, expérience qui renforce son admiration pour la culture, les valeurs, la discipline allemandes. Il 
participe aux guerres balkaniques, souhaitant contribuer à "moderniser l'armée hellénique». Durant la Première Guerre mondiale - qui provoque en Grèce un «schisme national»- Metaxás s'oppose au Premier ministre Vénizélos, refusant la participation du pays à la campagne des Dardanelles. De même que le roi Constantin, il défend une position de neutralité et d'alliance passive avec l'Allemagne, qu'il juge particulièrement puissante.

Il refuse également de s'associer à l'expédition en Anatolie (1919-1922), convaincu du manque de moyens et de préparation de l'armée hellénique. Il s'oppose là encore très vivement à E. Vénizélos, chef de file du Parti libéral ${ }^{13}$. Ce dernier incarne alors l'alliance avec les forces de l'Entente, mais aussi le républicanisme, la modernisation économique, l'expansionnisme territorial. Face à ce camp, le roi Constantin et les royalistes représentent plutôt une posture proallemande, une démocratie couronnée, un système économique plus traditionnel, le recentrage sur un État modeste, sans prétentions territoriales jugées irréalistes. Dans ce conflit interne, Metaxás prendra clairement le parti du roi. En 1920, il démissionne de l'armée et, après le désastre militaire du pays face à la Turquie (Traité de Lausanne, 1923) - un désastre qu'il avait prévu - il s'engage en politique.

\section{Un homme politique déçu et hostile au parlementarisme}

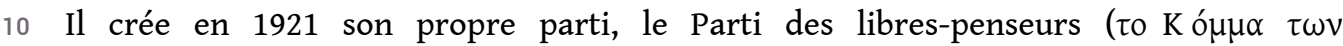
E $\lambda \varepsilon v \theta \varepsilon \rho \circ \varphi \rho o ́ v \omega v)$. La formation se présente comme une «troisième voie » entre les partis vénizéliste et royaliste, qui dominent alors la vie politique. Il propose de faire table rase d'un passé estimé " honteux », humiliant, d'impulser une "régénération du pays ", avec l'aide d'hommes « nouveaux » ${ }^{14}$.

11 De 1923 à 1935, dans un climat d'instabilité ponctué par plusieurs coups d'État, ce parti reste très marginal, en dépit d'une percée ( $15,68 \%$ des voix) aux législatives de $1926^{15}$. Aigri par ses faibles succès électoraux, I. Metaxás prône le retour de la monarchie. Le plébiscite du 3 novembre 1935 et le retour du roi Georges II sur le trône jouent en sa faveur ${ }^{16}$ : le 13 avril 1936, le roi lui propose le poste de Premier ministre.

12 L'instabilité sociale - et notamment la tenue d'une grève générale, prévue le 5 août ${ }^{17}$ lui permet avec l'appui du roi Georges II, de suspendre plusieurs articles de la Constitution et d'établir une dictature le 4 août 1936: le Parlement est suspendu, les partis politiques et la grève sont interdits, la censure est imposée, les principaux chefs du camp vénizéliste, les membres du parti communiste sont arrêtés et exilés ${ }^{18}$.

\section{Encadrer, discipliner et mobiliser la nation}

13 Le « régime du 4 août » entend toutefois s'appuyer sur un idéal mobilisateur, celui d'une Grèce "régénérée ": la construction d'une "Troisième civilisation hellénique " est érigée en slogan, remodelant dans une logique de cohésion interne l'ancien projet irrédentiste de la Grande Idée, projet ébranlé par la «Catastrophe » micrasiatique de 1922. Les deux civilisations précédentes, racines du renouveau national sont d'une part la Grèce ancienne classique - et l'accent est moins placé sur Athènes que sur Sparte, Cité réputée guerrière et disciplinée; d'autre part, la civilisation "médiévale grecque byzantine », marquée par la religion et la culture chrétiennes orthodoxes. 
14 Le régime exalte la patrie ${ }^{19}$, la communauté biologique $(\varphi \nu \lambda \eta ́ n)^{20}$, l'unité sociale ${ }^{21}$, la jeunesse, la famille ${ }^{22}$, la religion, le modèle du soldat, les vertus viriles, le culte du chef $^{23}$, l'idée de régénération ${ }^{24}$. Monarchiste ${ }^{25}$, il condamne le système parlementaire et partisan ${ }^{26}$.

15 Au plan familial, le régime propose un système patriarcal et traditionnel, qui distingue clairement les rôles de l'homme - valorisé par son dynamisme, sa force physique, son caractère discipliné et moral - de la femme. Celle-ci est également mise en valeur, mais plutôt dans un rôle de mère et d'épouse vertueuse ${ }^{27}$.

16 Le régime est fondamentalement anticommuniste ${ }^{28}$. Il se pose pourtant comme État " populaire », social, hostile au règne démesuré de l'argent (ploutocratie) ${ }^{29}$, un État au service des ouvriers, des agriculteurs, des travailleurs ${ }^{30}$. Le «Chef $»^{31}$ ne se présente-t-il pas lui-même comme le "Premier Ouvrier », ou le «Premier Paysan » du pays ${ }^{32}$ ? Le régime s'inspire du modèle corporatiste et paternaliste, qui confère un rôle de l'État dans la vie économique, sans mettre en question le système commercial, industriel et financier jusqu'alors en vigueur ${ }^{33}$. L'iconographie, les discours exaltent aussi la vie agricole, les liens à la nature, aux champs ${ }^{34}$, si bien que de Metaxás est aujourd'hui considéré par certains comme l'un des précurseurs du mouvement écologique en Grèce contemporaine ${ }^{35}$.

17 Ces éléments apparaissent abondamment dans la presse du régime - dont les revues

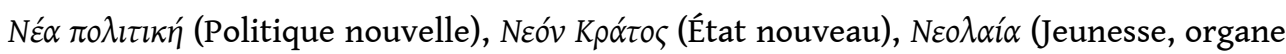
de l'Organisation nationale de la jeunesse) - dans les discours, photographies et affiches diffusés par le pouvoir ${ }^{36}$.

Les expériences des pays voisins - Portugal, Italie, Allemagne - ont représenté des sources d'inspiration. Dans son journal, I. Metaxás considère en effet :

La Grèce depuis le 4 août est devenue un État anticommuniste, un État antiparlementaire, un État totalitaire. Un État fondé sur le monde agricole et ouvrier et par conséquent un État hostile au règne de l'argent. Bien sûr, cet État ne dispose pas d'un parti spécifique qui gouvernerait le pays. Mais le parti c'est le Peuple tout entier, à l'exception des incorrigibles communistes et des réactionnaires des anciens partis ${ }^{37}$.

19 Le régime de Metaxás a donc bien repris, en se les appropriant, des aspects clés du régime fasciste italien. 
Figure 1 : loannis Metaxás salué par l'armée et des membres du gouvernement, janvier 1939

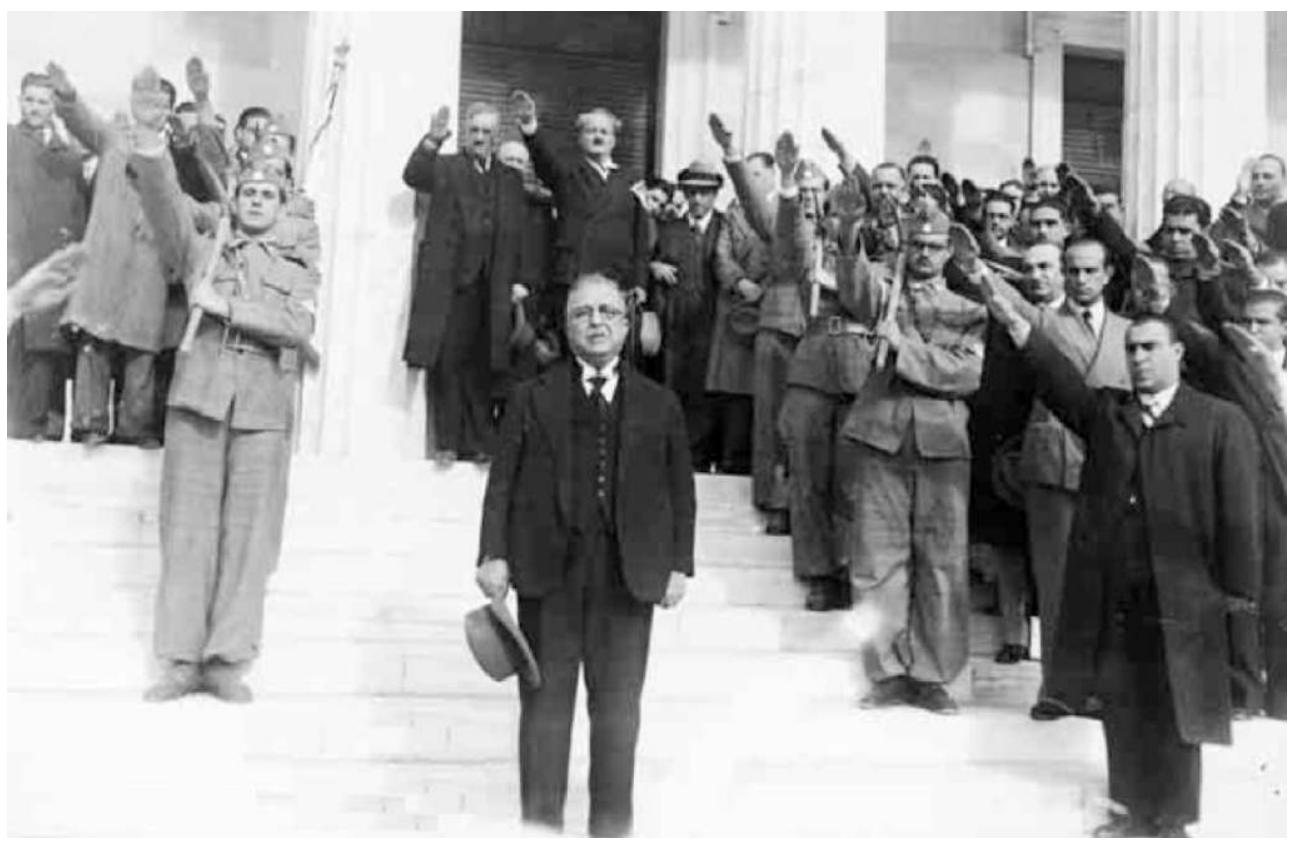

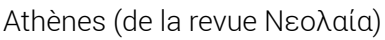

\section{Ambitions et insécurité personnelle : Dieu, une force de soutien}

Le journal de Metaxás - qui laisse entrevoir des traditions familiales, un parcours, des sensibilités - transmet l'image d'un homme croyant, profondément respectueux de la religion. Dans ses notes, Ioannis Metaxás se réfère volontiers à Dieu, dont il demande l'aide ${ }^{38}$. Dans ses discours publics, il met l'accent sur les traditions chrétiennes, sur la nécessité pour les jeunes de croire en Dieu ${ }^{39}$. Dans une allocution prononcée à l'Université d'Athènes le 20 novembre 193740, il souligne à quel point l'Empire byzantin, «moins impressionnant que la civilisation grecque antique quant aux arts et aux sciences », aurait été « infiniment supérieur au plan religieux, édifiant un idéal (...) qui nous a maintenus et nous maintient encore tous ensemble $»^{41}$.

\section{Le christianisme grec orthodoxe, pilier du régime du 4 août}

\section{Religion et régénération spirituelle de la nation}

21 La religion est donc érigée en pilier du régime et - après des décennies "d'intrigues 》 et "d'ébranlement des valeurs»- en facteur de régénération spirituelle nationale ${ }^{42}$. Dans une allocution aux enseignants le 28 octobre 1936 à l'Université de Salonique, le chef du gouvernement précise :

Ce que je souhaite de vous, c'est que (ces jeunes) croient en la puissance supérieure de Dieu et qu'ils s'y soumettent. Je veux qu'ils vivent comme des chrétiens. Vous ne pouvez pas, vous, enseignants grecs, qui travaillez dans les écoles du primaire et du secondaire, rester neutres ou indifférents à l'égard de la religion (...). Ceci serait clairement une tentative de rendre ces élèves athées ${ }^{43}$.

L'orthodoxie est posée en gardienne de l'âme grecque. Les revues du régime articulent étroitement nation et christianisme orthodoxe, dans une logique d'exaltation 
patriotique $^{44}$. Certes minoritaires dans le pays, les autres religions ne sont pas évoquées.

\section{L'Église chrétienne orthodoxe, pilier du régime}

Église « dominante » depuis la naissance de l'État en $1830^{45}$, l'Église orthodoxe de Grèce doit, selon Metaxás, jouer un rôle accru en tant qu'instance étatique, guide moral, instance éducative et force d'encadrement: il s'agit de "revaloriser» le clergé et "d'ancrer plus solidement le sentiment religieux qui a sauvegardé l'hellénisme durant de longs siècles $»^{46}$. Dans cet effort d'encadrement, de mobilisation de la société, le régime s'appuie donc sur le haut clergé orthodoxe.

Après avoir reconnu le régime, apprécié son projet de revalorisation des idéaux orthodoxes et de lutte contre le communisme ${ }^{47}$, le Synode de l'Église de Grèce, dans une encyclique datée du 19 décembre 1936, appelle le peuple grec et le clergé à " honorer le roi et à obéir aux pouvoirs légitimes, afin de préserver la paix sociale $»^{48}$. Cette circulaire vise-t-elle alors à apaiser un front de résistance ?

Le régime du 4 août fait adopter une nouvelle charte de l'Église (orthodoxe) de Grèce, confirmant les fortes relations entre Église et État. Il restructure la Caisse d'assurance sociale du clergé orthodoxe. Il fonde la Mission intérieure (Apostoliki Diakonia) de l'Église orthodoxe ${ }^{49}$, un organisme envisagé depuis le début des années 1930 par la haute hiérarchie. L'objectif de cette instance serait de "renforcer les vertus spirituelles» de la population, de combattre le communisme et les hérésies notamment le millénarisme/les Témoins de Jéhovah ${ }^{50}$. Sous le régime Metaxás, l'Église se voit également reconnaître la propriété de terres acquises durant la période ottomane. L'État, qui a désormais intégralement pris en charge le salaire du clergé orthodoxe, subventionne les organisations de jeunesse chrétienne, limite le prosélytisme non orthodoxe et renforce l'application de la loi de 1924 sur le repos dominical ${ }^{51}$. 
Figure 2 : Icône orthodoxe de Jésus Christ

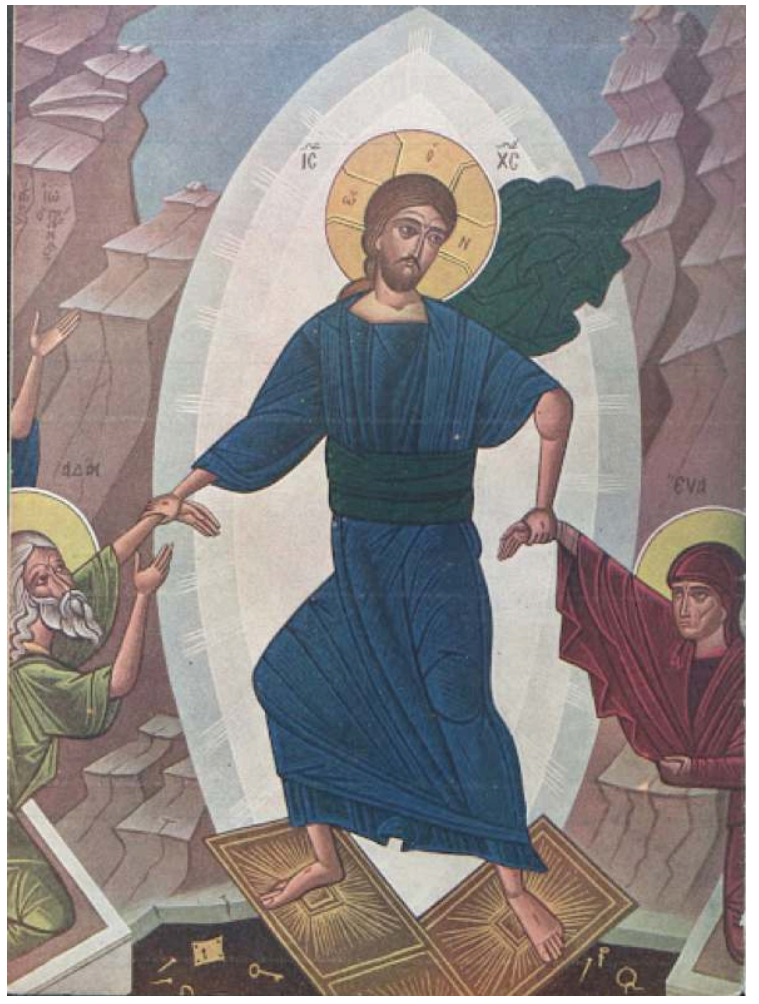

Neoגaía, 8 avril 1939, p. 856.

Ce type de rapports entre religieux et politique - renforcé certes de 1936 à 1941 inscrit pourtant ce régime dans la continuité, beaucoup plus que dans la rupture au regard des expériences politiques précédentes en Grèce contemporaine ${ }^{52}$.

\section{L'Organisation nationale de la Jeunesse (EON), enfant chéri du général Metaxás}

De même que Mussolini ou Hitler, Metaxás a fortement misé sur la jeunesse ${ }^{53}$ pour consolider le régime ainsi que sa propre autorité. Ne possédant pas à l'été 1936 de grand parti de masse, le «Chef » fonde en novembre 1936 l'Organisation de la Jeunesse nationale (EON), conçue comme une «aristocratie politique nationale». À travers les activités physiques et l'enseignement, elle vise à former les jeunes « au plan moral et national», à développer «le sentiment national, la foi religieuse, l'esprit de coopération et de solidarité, la spécialisation professionnelle ", et ceci " conformément aux orientations sociales et politiques du régime du 4 août $»^{54}$.

Les jeunes - garçons et filles - de l'EON portent l'uniforme et sont structurés en pionniers (de 9 à 13 ans), en phalangistes (de 19 à 25 ans) ${ }^{55}$. Des milices de travail

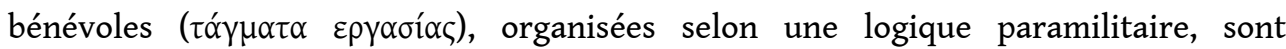
également établies à Athènes en 1937 sous l'impulsion du ministre de la Capitale et ancien maire d'Athènes Konstantinos Kotzias ${ }^{56}$, admirateur de l'Italie fasciste et de l'Allemagne nazie.

Selon l'article 3 de la Charte de l'EON, l'adhésion à l'Organisation est ouverte «à tous les citoyens chrétiens de nationalité grecque, quel que soit leur sexe, de 8 à 25 ans " $^{57}$. Le 5 janvier 1939, lors du premier Congrès de l'EON à Athènes, le chef du gouvernement rappelle les mots d'ordre de l'Organisation: «le Roi! La Patrie! La Religion! La 
Famille! La Renaissance de la Grèce $\aleph^{58}$. Metaxás y confirme que l'EON est une " organisation fondamentalement chrétienne orthodoxe ", qui doit "aider l'Église " Après la fin de 1936, Metaxás sollicite des écoles, des enseignants, des associations chrétiennes qu'ils participent activement au recrutement au sein de l'Organisation. À la fin des années 1930, les publications de l'EON ${ }^{60}$ sont utilisées comme matériel pédagogique dans les écoles publiques ${ }^{61}$.

\section{L'altérité, une menace pour la nation?}

\section{Les non chrétiens exclus de la « race/nation » grecque?}

La «Troisième civilisation hellénique » semble a priori exclure les non chrétiens de la nation ( $\left.\varepsilon^{\prime} v{ }^{\prime} \varsigma, \pi \alpha \tau \rho i ́ \delta \alpha\right)$ - voire de la race ( $\left.\varphi \nu \lambda \eta ́\right)$ - grecques ${ }^{62}$. Cette représentation de la communauté nationale, là encore, ne constitue pas une nouveauté. Lorsqu'il s'adresse aux membres de l'EON, Metaxás leur demande d'agir «avec la foi, en tant que chrétiens, car la très grande majorité d'entre vous sont des chrétiens ${ }^{63}$. Dans son ouvrage Idéologie et orientation de l'État nouveau, l'un des idéologues du régime, Giorgos Mandzoufas, considère la nation comme une "union religieuse ", "un corps de personnes liées par des coutumes (...), des origines raciales, la langue, des intérêts ${ }^{64}$. L'auteur semble pourtant admettre la possibilité de « devenir Grec » ${ }^{65}$.

\section{Les minorités culturelles, injures à l'unité nationale?}

31 Le rejet des anciens clivages partisans et sociaux, la promotion de l'unité nationale portent le régime du 4 août à envisager toute dissidence - politique, mais aussi culturelle- comme un facteur de vulnérabilité6. Le pays compte alors des communautés musulmanes albanophones en Épire et en Macédoine (entre 25000 et 45000 personnes), des communautés musulmanes turcophones et slavophones en Thrace occidentale (environ 100000 personnes), des juifs (environ 73000 sont recensés en 1928 dont 63000 d'origine sépharade) ${ }^{67}$. Ce regard négatif sur l'altérité - regard renforcé par des considérations de politique extérieure ${ }^{68}$ - transparaît par exemple dans la politique de mise à l'écart, de contrôle militaire renforcé des zones montagneuses du Nord du pays : des zones proches de l'Albanie, proches de la Bulgarie surtout et de la Turquie ${ }^{69}$.

\section{Les Slavo-Macédoniens, cible d'une politique d'assimilation nationale}

Cette attitude a plus spécialement visé les slavophones de Macédoine d'abord (près de 200000 personnes, essentiellement chrétiennes orthodoxes) ${ }^{70}$ et de Thrace (chrétiens et musulmans). Le fonds Metaxás des archives de l'État hellénique témoigne du souci de réduire de manière décisive la bulgarophonie en Macédoine. Cette préoccupation s'insère dans une politique d'assimilation nationale et linguistique d'autant mieux assumée qu'elle concerne des populations orthodoxes ${ }^{11}$.

L'inspecteur des écoles primaires I. Papadopoulos, auteur de rapports pour le Ministère, met l'accent sur le rôle clé que doivent jouer les organisations de jeunesse pour "cultiver les idées nationales et patriotiques en Macédoine occidentale ». Or, selon lui, leur rôle serait "crucial parmi les slavophones". Le rapporteur signale pourtant qu'en 1938, les slavophones seraient «peu disposés à entrer dans l'EON 
malgré les efforts des responsables politiques et scolaires » et ceci " contrairement aux réfugiés chrétiens orthodoxes ", arrivés en 1923 d'Anatolie et de Thrace orientale ${ }^{72}$.

Sur ce point encore, la ligne de continuité l'emporte entre ce régime et les gouvernements antérieurs. La seconde partie de cet article tendra à nuancer l'idée d'une parfaite entente entre le haut clergé orthodoxe et Métaxas. Les discours de tolérance religieuse de ce dernier, ses rapports aux communautés juives seront par ailleurs examinés.

\section{La « tolérance religieuse » du régime metaxiste : enjeux et débats}

\section{Valorisation ou subordination des institutions chrétiennes du pays ?}

\section{Metaxás et le projet de création d'un parti chrétien national-social}

L'entre-deux-guerres s'ouvre en Grèce par un traumatisme national, la défaite militaire en Anatolie. Dans la foulée, un million et demi de réfugiés chrétiens affluent sur le territoire hellénique, tandis que plus de 800000 musulmans, souvent hellénophones, partent précipitamment vers la Turquie ${ }^{73}$.

La deuxième République grecque, de 1924 à 1935, est marquée par le développement d'associations chrétiennes, confréries de théologiens laïcs. Ces groupes sont proches de l'Église orthodoxe, mais échappent partiellement au contrôle du Synode des évêques. Durant ces années, il faut notamment signaler l'essor considérable de l'association Zwń (Zoï, La vie). Formée en 1907, cette association a mis l'accent sur les théologiens laïcs, à travers un réseau de croyants activistes ${ }^{74}$ : les cadres de Zoï animent des groupes d'enseignement et de discussion religieuse, des centres de vacances, des organisations de jeunesse, publient ${ }^{75}$. Or, tandis qu'émerge le parti communiste de Grèce $^{76}$, ces associations s'orientent vers un projet de "réévangélisation » de la société, projet également conçu dans une logique d'endiguement des «valeurs politiques subversives".

Au cours des années 1930 - avec pour point culminant l'été 1936 - la création d'un parti politique chrétien semble, en fait, sur le point d'aboutir. Le Synode des évêques orthodoxes de Grèce ne semble pas avoir été à l'initiative de ce projet, d'abord promu par des intellectuels laïcs, tel Michaïl Galanos, contributeur majeur de la revue

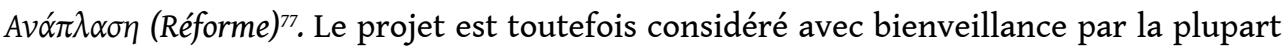
des évêques orthodoxes et est soutenu par plusieurs d'entre eux ${ }^{78}$.

Cette formation - qui porterait le nom de Front chrétien national-social - vise une « rechristianisation de la vie publique, des institutions étatiques, spécialement l'éducation et la justice»: moralisation de la vie sociale et politique; élévation du «niveau spirituel, moral et politique du Parlement hellénique »; soutien actif à la monarchie, promotion d'un interventionnisme étatique dans le domaine social et économique, ceci afin de renforcer la justice sociale ; rejet de la lutte des classes ; respect de la propriété privée et de la richesse; mise en valeur de la dimension théologique - plus que politique - de la liberté. Le parti se prononce également pour une pleine indépendance de l'Église pour ce qui concerne son administration interne, tout en prônant le maintien d'une rémunération par l'État du clergé orthodoxe ${ }^{79}$. Cette position rejoint exactement les efforts de la direction de l'Église orthodoxe de Grèce. Celle-ci cherche 
depuis quelques années à consolider ses compétences législatives pour les questions touchant à la religion et à l'Église ${ }^{80}$. Le parti prône également une "tolérance" à l'égard des minorités ethniques et religieuses ${ }^{81}$.

Or, Metaxás - qui a entretemps interdit syndicats et partis politiques - bloquera la formation de ce parti, pourtant proche des idéaux du régime ${ }^{82}$.

\section{Alliance ou concurrence avec l'Église pour le patronage de la jeunesse ?}

L'intérêt de Metaxás pour la jeunesse ${ }^{83}$ dessine a priori une forte coopération avec d'autres personnalités ou instances: l'éducation publique étatique et le personnel enseignant, la famille royale et bien sûr l'Église. Un premier axe fort semble donc lier le gouvernement Métaxas, le Palais et l'Église autour de la formation des jeunes chrétiens: des évêques orthodoxes ainsi que des membres de la famille royale n'assistent-ils pas régulièrement aux défilés des sections de l'EON?

Les cours de religion dans les écoles publiques, centrés sur le christianisme orthodoxe; les cours de catéchisme et les activités d'instances contrôlées par le Synode; enfin l'Union des jeunes chrétiens (XAN, XEN) - membres de l'organisation mondiale des Jeunesses chrétiennes (YMCA) : ces éléments attestent le souci de l'Église orthodoxe pour l'éducation des jeunes du pays. Durant l'entre-deux-guerres, le prince Paul, futur héritier du trône, s'est par ailleurs investi dans le patronage des organisations de jeunes scouts ${ }^{84}$.

Or, Métaxas a cherché à reprendre un contrôle ferme sur la jeunesse. Cette démarche n'a pu que susciter des tensions avec la famille royale et avec le Synode. Ainsi, en 1938, les anciennes organisations de jeunesse - dont les sections de scouts - sont dissoutes et fusionnent avec l'EON, directement dévouée au "Chef » ${ }^{85}$. La préoccupation de Metaxás pour l'enjeu éducatif - importance dont témoigne, à l'automne 1938, une reprise en charge du portefeuille de l'Éducation nationale ${ }^{86}$ - s'est traduite par un interventionnisme accusé dans ce domaine et une pression sur le personnel enseignant du pays ${ }^{87}$.

\section{La mise au pas de la haute hiérarchie ecclésiastique}

D'un point de vue circonstanciel, fin 1938, le choix de cumuler les fonctions de chef du gouvernement et de ministre de l'Éducation reflèterait aussi l'intention d'accentuer une mainmise sur l'Église (orthodoxe) de Grèce, Église rattachée à ce ministère. Ainsi, dans son discours, en novembre 1938, Metaxás précise qu'il s'agit aussi : « de restaurer l'ordre dans l'Église », un ordre apparemment troublé par de "récents événements ", afin que ceux-ci « ne se reproduisent plus à l'avenir $»^{88}$.

Après avoir vivement rappelé à l'ordre le métropolite de Kozanis (Macédoine) - dont un texte suggérait un clivage social entre le Nord et le Sud du pays ${ }^{89}$ - Metaxás intervient dans l'élection du nouvel archevêque d'Athènes en 1938. Après la mort de Chrysostomos Papadopoulos (1924-1938), le Synode a en effet élu, à une voix d'avance, l'évêque de Corinthe Damaskinos Papadopoulos. Cet influent homme d'Église - un temps impressionné par les succès de l'Italie fasciste et sa capacité à « rassembler les forces nationales dans un combat résolu $»^{90}$ a été élu métropolite en 1923. Cet évêque dynamique, fin politique est néanmoins suspecté de sympathies vénizélistes ${ }^{91}$. 
Metaxás, confronté sur cette question à des divergences au sein du gouvernement, pousse plusieurs métropolites à solliciter l'invalidation de l'élection ${ }^{92}$. Aidé par un Synode remanié et sous contrôle, il parvient à faire prévaloir le principal concurrent de Damaskinos, Mgr Chrysanthos Philippidis, métropolite de Trébizonde. Ce dernier, évêque prestigieux, est alors connu pour sa loyauté à la monarchie ${ }^{93}$. Si Metaxás a défendu l'indépendance de l'Église dans ses discours, il semble qu'il n'ait, au final, pu tolérer la promotion d'un archevêque qu'il n'appréciait pas ou qu'il craignait. Metaxás aurait donc autant souhaité une Église «revalorisée» qu'une Église fermement subordonnée et obéissante.

\section{Ingéniérie sociale, gestion des minorités et tolérance religieuse}

\section{Un appel au respect de l'altérité religieuse : politique active ou simple rappel à l'ordre?}

Dans plusieurs de ses allocutions, Metaxás met en avant - outre les valeurs de discipline - celles de solidarité, d'entraide, de partage et de respect de l'autre ${ }^{94}$. Dans un important discours, prononcé au Congrès de l'Organisation nationale de la Jeunesse le 5 janvier 1939, le chef du gouvernement rappelle que l'EON est par définition une « organisation chrétienne orthodoxe ». Il précise toutefois :

Cela ne signifie pas que nous ne respectons pas les convictions religieuses des autres. Simplement nous voulons dire que notre Organisation est chrétienne et qu'elle représente en premier lieu le dogme orthodoxe. Sur ce point, je pense qu'il n'y a rien à discuter, si ce n'est la nécessité d'éviter avec soin, avec grand soin, tout acte susceptible de blesser les convictions religieuses des ressortissants de ce pays qui ne sont pas chrétiens. À cet égard, je voudrais vous dire que les membres de la Jeunesse qui porteraient atteinte aux convictions religieuses d'autrui, je ne les considèrerais plus comme membres de l'EON ${ }^{95}$. Le respect des croyances des nonchrétiens doit être absolu. Et cela s'entend - je voudrais attirer toute votre attention là dessus- si des parents, quoique non chrétiens, veulent de toute leur âme que leurs enfants entrent dans l'organisation, en pleine conscience qu'il s'agit évidemment d'une organisation purement chrétienne et si leurs enfants le souhaitent également, et bien il nous faut examiner avec bienveillance leur souhait, en s'assurant que ce souhait ne soit l'effet d'aucune pression des parents, aussi minime soit-elle, et ceci en traitant chaque demande au cas par cas (...). Pour le reste, l'EON devra être exemplaire pour son amour et sa soumission à notre Église, de même qu'elle devra participer aux cérémonies religieuses afin de montrer de cette manière son respect absolu à l'égard de la religion (...). Je peux dire que notre Église a toujours été pour nous une assistante enthousiaste. Mais c'est aussi le cas des établissements éducatifs de l'Église catholique - y compris tout récemment puisque j'ai repris le ministère de l'Éducation - ces établissements religieux ont fait preuve d'un grand empressement pour aider le développement de l'Organisation et exhorter les enfants (catholiques) à s'y intégrer ${ }^{96}$.

Ce texte indique clairement qu'à la fin des années 1930, l'EON inclut non seulement des chrétiens orthodoxes, mais aussi, en plus faible nombre certes, des chrétiens d'autres dogmes, notamment des catholiques romains. Ce document suggère par ailleurs que l'adhésion de non-chrétiens était jugée possible, du moins pour Metaxás : à condition, toutefois, que le jeune et surtout ses parents soient pleinement informés et acceptent le caractère « purement chrétien » de l'organisation.

Sans même prendre en considération les pratiques - et notamment les possibles rejets de la part des responsables locaux de l'EON ${ }^{97}$ - ces restrictions et la nature clairement 
confessionnelle de cette structure ont probablement découragé nombre de parents non-chrétiens. Si des cas d'intégration de musulmans n'ont pas été jusqu'ici mis au jour, en revanche, certains jeunes juifs auraient été intégrés dans l'EON ${ }^{98}$.

En insistant sur ce message d'acceptation pleine de l'altérité religieuse, il faut aussi s'interroger sur la signification, l'ampleur et les conséquences d'une telle attitude. Dans un contexte de radicalisation xénophobe, de tensions interconfessionnelles, ce discours a-t-il représenté un axe constructif ou n'a-t-il constitué qu'un rappel à l'ordre, derrière lequel transparaît en creux un climat diffus de refus de l'autre, spécialement parmi les jeunes?

Ce discours de respect des convictions religieuses d'autrui a-t-il impliqué une politique active ou s'est-il limité au registre - non négligeable - des paroles, des recommandations? Le régime de Métaxas s'est-il distingué par une politique de tolérance religieuse, de protection des minorités confessionnelles ?99

\section{L'absence de législation antisémite}

51 Contrairement à l'Allemagne nazie ${ }^{100}$ ou à l'Italie mussolinienne ${ }^{101}$, la Grèce metaxiste n'aurait pas adopté de véritable législation antisémite. Comme le montre Bernard Pierron, les rapports entre juifs et chrétiens en Grèce ont été complexes depuis 1821. Si la législation du pays a souvent été libérale, si des intellectuels ont promu l'intégration pleine des non-chrétiens - et notamment des juifs - dans l'État, la société, la présence d'un antisémitisme diffus est attestée depuis les révoltes de $1821^{102}$.

52 Ces sentiments semblent se conforter dans l'entre-deux-guerres, portés par l'afflux considérable de réfugiés chrétiens, par la virulence des clivages politiques, par la dépression économique et l'essor des discours de haine en Europe. Ainsi, au début des années 1930, les frictions se multiplient dans le Nord du pays entre citoyens juifs et anciens réfugiés orthodoxes d'Anatolie. Une grande partie de ces derniers est pauvre et se heurte au mépris des Grecs " autochtones ». Des organes tels l'Union nationale Grèce

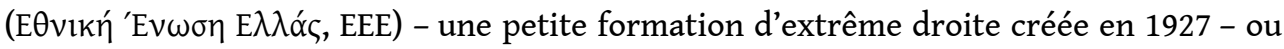

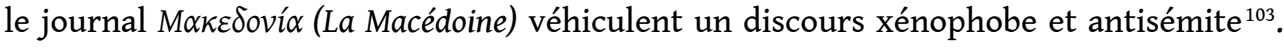
Le 29 juin 1931 - peu avant que la Thrace turque voisine ne soit, elle aussi, touchée par plusieurs pogroms anti-juifs ${ }^{104}$ - les émeutes de Campbell débouchent sur la mise à feu du quartier juif de Salonique par des chrétiens nationalistes, détruisant nombre de maisons et de commerces ${ }^{105}$. La communauté juive de Salonique - environ 56000 personnes $^{106}$, plus de $40 \%$ de la population de la ville - représente alors une communauté hétérogène. Durant l'entredeux-guerres, les juifs de Salonique auraient été plutôt favorables aux royalistes et méfiants à l'égard d'E. Vénizélos, perçu comme « antisémite ».

Après l'important incendie de 1917, Salonique est, en effet, restructurée de manière à affirmer son caractère "hellénique ». Ainsi, dans une ville jusqu'alors largement paralysée le samedi, le dimanche est imposé comme jour de repos (loi de 1924), la langue grecque devient obligatoire ${ }^{107}$, des portions du cimetière juif sont expropriées pour construire l'Université, ceci sous la houlette de gouvernements libéraux/ vénizélistes ${ }^{108}$. C'est également sous un gouvernement d'inspiration vénizéliste que sont institués, à partir de 1923, des collèges électoraux séparés pour les juifs de Salonique et les musulmans de Thrace, loi qui, à l'appel de la communauté juive, sera invalidée en 1933 par la Cour suprême ${ }^{109}$. 

nuancée. En effet, durant tout son mandat, l'ancien général a tenu à maintenir une position de neutralité favorable vis-à-vis de l'Allemagne nazie. Si la censure médiatique constitue alors un aspect de la politique interne de la Grèce ${ }^{118}$, le régime interdira tout article négatif concernant l'Allemagne. D'ailleurs, en fin novembre 1938, après la visite d'un diplomate allemand au ministère des Affaires étrangères hellénique, I. Metaxás émet une directive précisant que "la presse grecque ne publiera rien que le gouvernement allemand n'apprécierait pas ${ }^{119}$. Certes, dans les années 1930, l'Allemagne dispose d'un considérable pouvoir d'intimidation en Europe, a fortiori sur les petits États. Au demeurant, des injonctions du pouvoir à l'adresse de la presse du pays, afin que celle-ci cesse toute " attaque » contre le chancelier Hitler, sont attestées en Grèce bien avant la dictature du 4 août ${ }^{120}$.

60 évoqué la persécution des juifs par l'Allemagne. Ainsi - exemple marquant - la couverture, par la presse hellénique, de la Nuit de Cristal (6-8 novembre 1938), reprend la version officielle nazie ${ }^{121}$. Parallèlement, les brochures nazies, valorisées ${ }^{122}$, auraient été librement distribuées en Grèce ${ }^{123}$. À moins de pouvoir écouter la $\mathrm{BBC}$ - radio 
accessible alors à une infime minorité - la population du pays n'était aucunement informée de la politique nazie, en particulier des mesures de persécution à l'encontre des juifs et d'autres groupes sociaux. Cette couverture médiatique bienveillante à l'égard du nazisme et surtout, ce manque criant d'information ont sans doute grandement facilité la tâche des forces d'occupation allemandes après mai 1941: en mars 1943, l'essentiel de la population juive de Grèce est déporté et disparaît dans les camps de concentration ${ }^{124}$. En ce sens, sur ces deux questions de l'ouverture religieuse et des rapports aux juifs, les positions, la politique de Metaxás ont été, au final, pour le moins ambigües. Elles reflètent aussi les pressions auxquelles était soumis alors l'État grec.

61 Ceci ne signifie pas que l'ancien Général était alors rejeté par la population. La thèse dominante, selon laquelle Metaxás était largement impopulaire et coupé des "masses " avant le 28 octobre 1940 mériterait sans doute d'être relativisée. En effet, si Metaxás apparaît moins charismatique que B. Mussolini, les effets des slogans officiels, de l'exaltation patriotique, l'encadrement social, les mesures socio-économiques ont aussi rapproché le Chef d'une partie des Grecs ${ }^{125}$ : l'ampleur des rassemblements accompagnant ses prestations et déplacements pourrait en attester. Selon l'historien P. Vatikiotis, les classes les plus pauvres du pays auraient été "indifférentes sinon satisfaites du régime $»^{126}$. Dans un ouvrage paru en 2006, S. Marketos souligne que dans les années 1930, B. Mussolini et le fascisme auraient fasciné en Grèce et ceci y compris au sein de la classe politique, autant dans le camp libéral que monarchiste ${ }^{127}$.

\section{Conclusion}

Pour revenir à notre interrogation initiale, le régime du 4 août a bien représenté un régime fascisant, une version hellénique, adoucie, du modèle fasciste ${ }^{128}$. Quant au rapport du politique au religieux, la période Metaxás s'inscrit, néanmoins, à bien des égards dans une tradition ancienne, enracinée depuis la fondation de l'État: une tradition de contrôle et d'usage, par le pouvoir, du facteur religieux et ecclésiastique ; la recherche d'une alliance entre autorité politique et autorités chrétiennes orthodoxes; une tradition ambiguë de tolérance religieuse, tradition mitigée par la confusion idéal-typique entre membre de la nation et membre de l'Église orthodoxe.

$63 \mathrm{Au} \mathrm{xxI}$ siècle, si la nouvelle génération grecque considère souvent avec dédain ce régime autocratique, cette période de l'histoire $\mathrm{du} \mathrm{xx}^{\mathrm{e}}$ siècle reste controversée. Depuis 2008, alors même que la crise financière confirme le discrédit des grands partis établis, Ioannis Metaxás tend à réapparaître, aux yeux de certains, comme un modèle. Fondée en 1980, la formation d'extrême droite Aube dorée (Xрvøń Avүท́) a réalisé une percée électorale en juin 2012. Le parti, qualifié de « néonazi » par la presse grecque ${ }^{129}$, a obtenu 18 sièges au Parlement et son chef, Nikolaos Michaloliakos, aujourd'hui incarcéré, est plus visible dans les médias depuis quelques années. Formés dans un tout autre environnement que celui des années 1930, les membres, les sympathisants d'Aube dorée ont repris le salut dit romain/fasciste. Ce rituel nous renvoie directement au régime du 4 août, qui réémerge en Grèce comme une référence pour quelques-uns ou comme une ressource, sélectivement mobilisée. 
Figure 4 : Nikos Michaloliakos, dirigeant du Parti Aube dorée salut son public

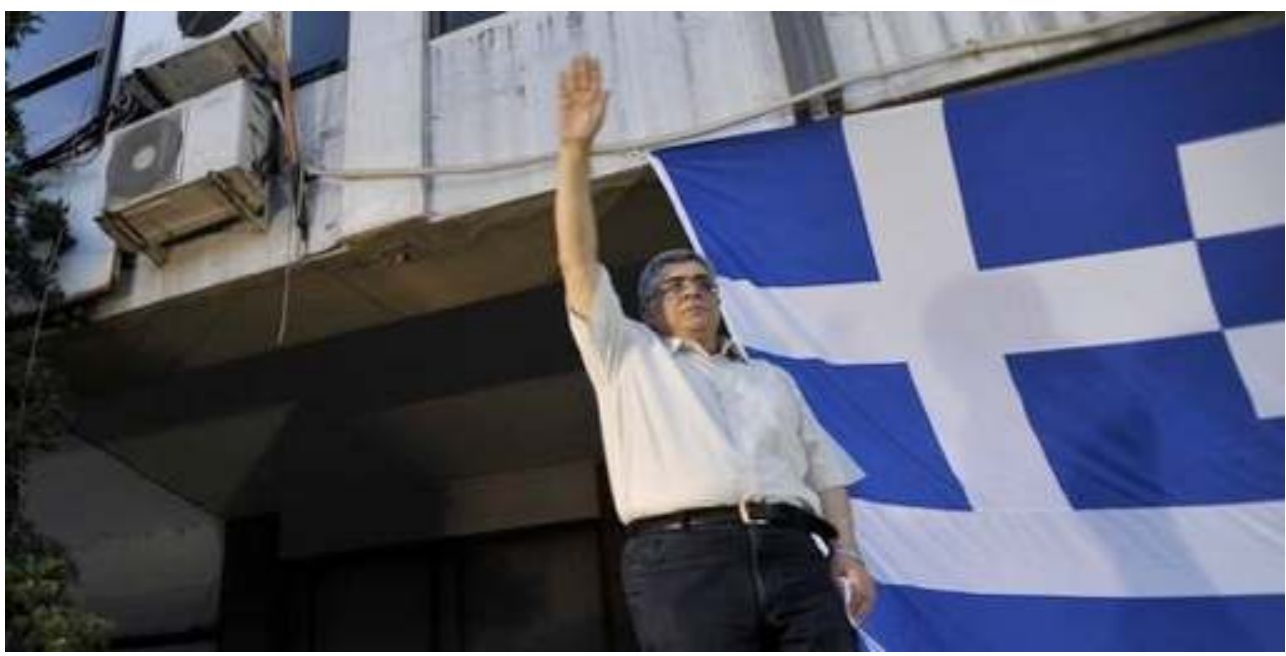

Athènes, juin 2012

\section{BIBLIOGRAPHY}

Anastassiadis Thassos, (2007), « Dieu vomit les tièdes! Modernisation ecclésiastique et intolérance religieuse : contribution sur la reconsidération des relations État-Église en Grèce dans l'entre-deux-guerres ", in Grivaud Gilles, Petmezas Socrate, (dir.), Byzantina-Moderna : Mélanges en l'honneur d'Hélène Antoniadis-Bibicou, Athènes : Alexandreia, p. 449-466.

Anastassiadou Méropi, (1997), Salonique 1830-1912, une ville ottomane à l'ère des réformes, Leyden : Brill.

Brustein William, (2003), Roots of Hate. Antisemitism in Europe Before the Holocaust, Cambridge: Cambridge University Press.

Burrin Philippe, (2003), La dérive fasciste, Paris : Seuil.

close David, (2006) Conservatism, Authoritarianism, Fascism in Greece 1915-1945, in Blinkhorn Martin, (dir.), Fascists and Conservatives. The Radical Right and the Establishment in xxth Century Europe, Londres: Unwin Hyman, pp. 205-215.

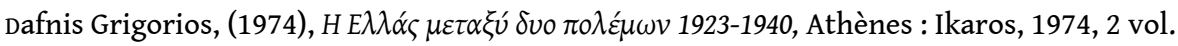
Dépret Isabelle, (2009), Église orthodoxe et histoire en Grèce contemporaine, Paris : l'Harmattan.

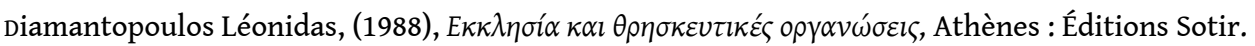

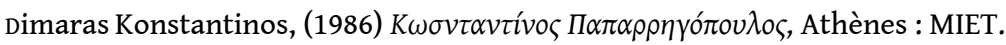

Eatwell Roger, (1996) "On Defining the Fascist Minimum. The Centrality of Ideology", Journal of Political Ideologies 1, pp. 303-319. 
Fleisher Hagen, (2006) “Authoritarian Rule in Greece 1936-1941 and Its Heritage”, Borejsza Jerzy, Ziemer Klaus, (dir.), Totalitarian and Authoritarian Regimes in Europe. Legacies and Lessons from the XXth Century, Oxford: Berghahn Books, pp. 237-275.

Forlin Olivier, (2013) Le fascisme. Historiographie et enjeux mémoriels, Paris : Découverte.

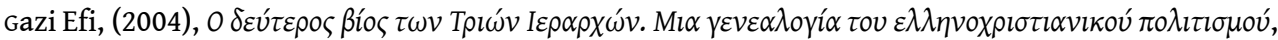
Athènes : Nefeli.

Gentile Emilio, (1990), "Fascism as Political Religion", Journal of Contemporary History 25, pp. 229-251.

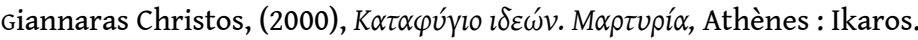

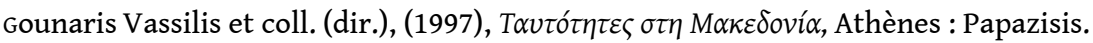

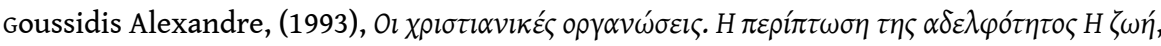
Salonique : Pournaras.

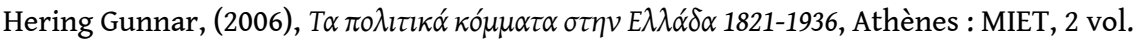
Houmourzios Stélios, (1972), No Ordinary Crown. A Biography of King Paul of the Hellenes, Londres: Weidenfield \& Nicolson.

Joakim G. Joakim, (2000) I. Metaxas. The Formative Years 1871-1922, Mannheim: Bibliopolis. Kallis Aristote, (2006), "Fascism, Charisma, Charismatisation. Weber's Model of Charismatic Domination and Interwar European Fascism", Totalitarian Movements and Political Religions 7, pp. 25-43.

Kallis Aristote, (2006), “The Jewish Community of Salonica Under Siege. The Antisemitic Violence of the Summer 1931", Holocaust and Genocide Studies 20.

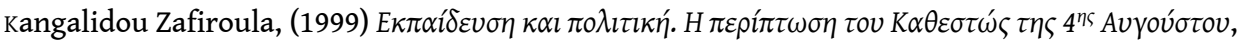
Salonique : Kyriakidis.

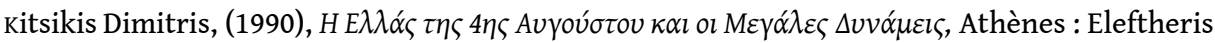
Skepsis.

Kofas Ioannis, (1993), Authoritarianism in Greece. The Metaxas Regime, New York: Columbia University Press.

Koliopoulos John, (1977), Greece and the British Connection 1935-1941, Oxford: Clarendon Press.

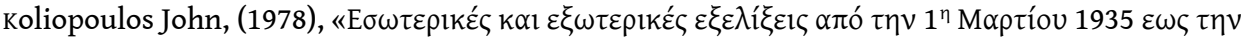

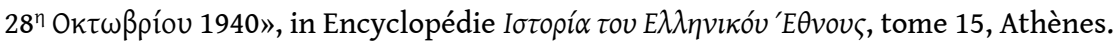

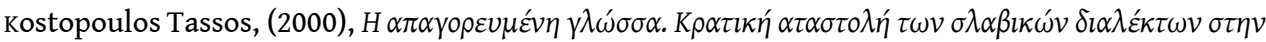

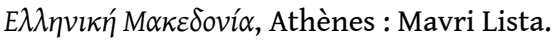

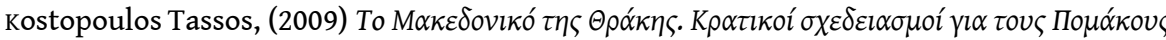
1956-2008, Athènes : Bibliorama.

Koubourlis Ioannis, (2005), La formation de l'histoire nationale grecque : l'apport de Spyridon Zambelios (1815-1881), Athènes : EIE-KNE.

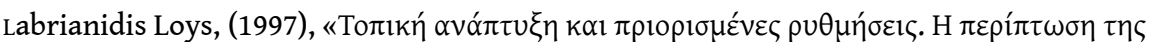

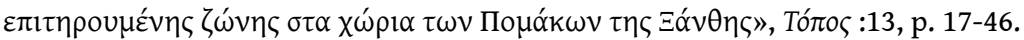

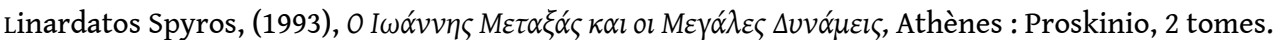




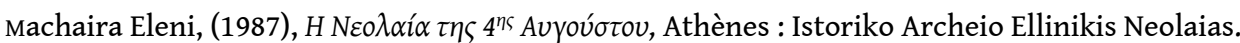

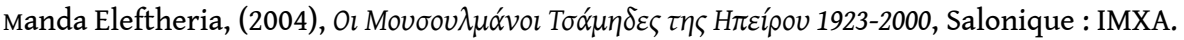

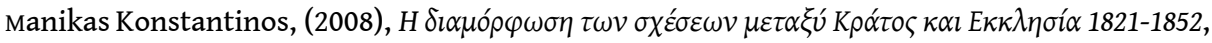
Athènes : Parrissia.

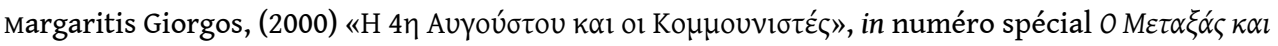

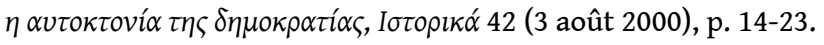

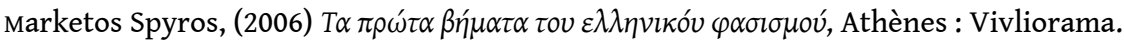

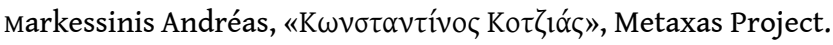

Markou Katerina, (2002), « Les Pomaques de Thrace grecque et leurs choix langagiers », Études balkaniques 9 (2002), p. 41-52.

Mavrogordatos Georges, (1983) Stillborn Republic. Social Coalitions and Party Strategies in Greece 1922-1936, Berkeley: California University Press.

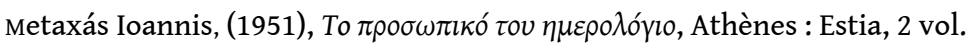

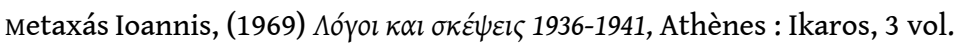

Milza Pierre, (2002), L'Europe en chemise noire. Les extrêmes droites en Europe de 1945 à aujourd'hui, Paris : Fayard.

Özkirimli Umut, sofos Spyros, (2008), Tormented by History. Nationalism in Greece and in Turkey, New York: Columbia University Press.

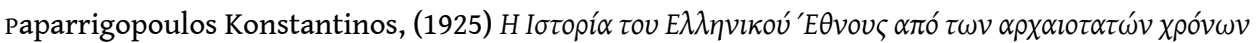

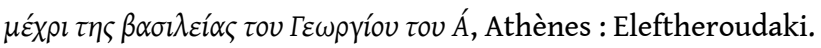

Payne Stanley, (1995) History of Fascism 1914-1945, Londres: UCL Press.

Paxton Robert, (2004), The Anatomy of Fascism, New York: Alfred Knopf.

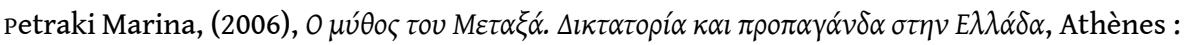

Okeanida.

pierron Bernard, (1996), Juifs et chrétiens de la Grèce moderne. Histoire des relations

intercommunautaires de 1821 à 1945, Paris : L'Harmattan.

Psilopoulos Eleni, (1965) La confrérie de théologiens Zoï, un mouvement spirituel en Grèce, Thèse de $3^{\mathrm{e}}$ cycle, Faculté de théologie de Strasbourg, 1965.

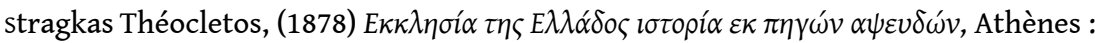

Papadogiannis.

sternhell Zeev, (2000), Ni droite, ni gauche. L'idéologie fasciste en France, Paris : Complexe.

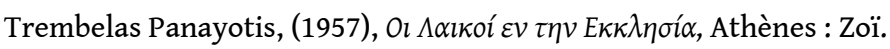

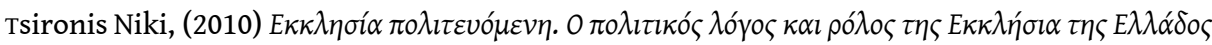
1913-1941, Athènes : Epikentro.

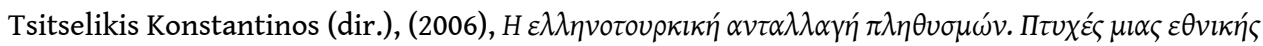

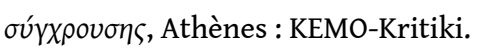

Tsitselikis Konstantinos, (2012), Old and New Islam in Greece, Leiden: Martinus Nijhof. Vatikiotis Panayotis, (1998), Popular Autocracy in Greece 1936-1941, Londres: Franck Cass, 1998. 
Vatikiotis Panayotis, (1993), "Metaxas, the Man”, in Higham Robin, VEREMIS Thanos, Aspects of Greece 1936-1940. The Metaxas Dictatorship, Athènes: Eliamep, pp. 179-191.

\section{NOTES}

1. I. Metaxás refuse l'ultimatum italien du 28 octobre 1940 en ajoutant : " Alors, c'est la guerre ». 2. Le 28 octobre a été érigé depuis en fête nationale et jour férié. Voir, entre autres, le

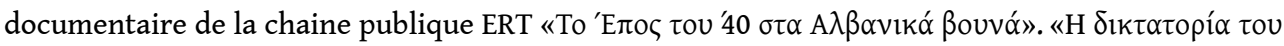

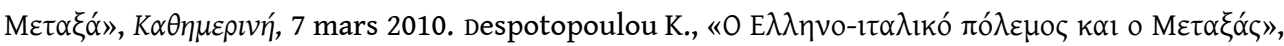

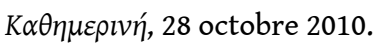

3. Outre le site largement apologétique Metaxas-Project et les écrits d'Andréas Markessinis, il faut ici mentionner l'initiative de l'archéologue Ioanna Foka - petite fille de I. Metaxás - qui a œuvré au rassemblement, à la numérisation et à la mise à disposition du public de fonds assez conséquent d'archives, de publications officielles, de discours et autres documents liés à son grand-père.

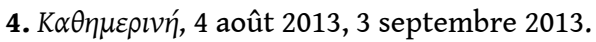

5. Forlin O., Le fascisme. Historiographie et enjeux mémoriels, Paris, Découverte, 2013. Milza P., Les fascismes, Paris, Seuil, 1991. Milza P., L'Europe en chemise noire. Les extrêmes droites en Europe de 1945 à aujourd'hui, Paris, Fayard, 2002. Burrin P., La dérive fasciste, Paris, Seuil, 2003. Paxton R., The Anatomy of Fascism, New York, Alfred Knopf, 2004. sternhell Z., Ni droite, ni gauche. L'idéologie fasciste en France, Paris, Complexe, 2000. Eatwell R., "On Defining the Fascist Minimum. The Centrality of Ideology", Journal of Political Ideologies 1 (1996), p. 303-319. Payne S, History of Fascism 1914-1945, Londres, UCL Press, 1995. Gentile E., “Fascism as Political Religion”, Journal of Contemporary History 25 (1990), p. 229-251.

6. Fleisher H., "Authoritarian Rule in Greece 1936-1941 and Its Heritage", в orejsza J., ziemer K. (dir.), Totalitarian and Authoritarian Regimes in Europe. Legacies and Lessons from the 19th Century, Oxford, Berghahn Books, 2006, pp. 237-275. Kallis A., "Fascism, Charisma, Charismatisation. Weber's Model of Charismatic Domination and Interwar European Fascism", Totalitarian Movements and Political Religions 7 (2006), pp. 25-43. vatikiotis P., Popular Autocracy in Greece 1936-1941, Londres, Franck Cass, 1998. Kofas I., Authoritarianism in Greece. The Metaxas Regime, New York, Columbia University Press, 1993. vatikiotis P., "Metaxas, the Man", in Higham R., veremis T., Aspects of Greece 1936-1940. The Metaxas Dictatorship, Athènes, Eliamep, 1993, pp. 179-191. close D., "The Power Base of the Metaxas Dictatorship", Ibid., pp.15-38. close D., Conservatism, Authoritarianism, Fascism in Greece 1915-1945, in Blinkhorn M. (dir.), Fascists and Conservatives. The Radical Right and the Establishment in 19th Century Europe, Londres, Unwin Hyman, pp. 205-215.

7. Celle-ci aurait été marquée par la recherche d'un équilibre entre sympathies pro-allemandes et attachement aux liens traditionnels et stratégiques avec la Grande Bretagne. Voir entre autres :

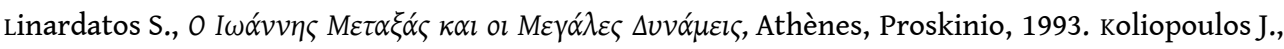

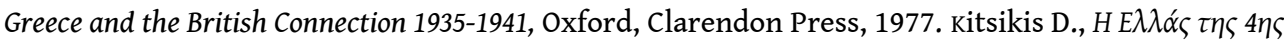

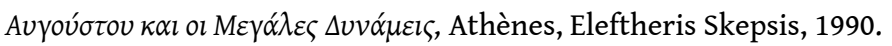

8. Son père est vice-préfet de l'île d'Ithaque, mais perd son poste peu après la naissance de Ioannis. La famille émigre à Céphalonie.

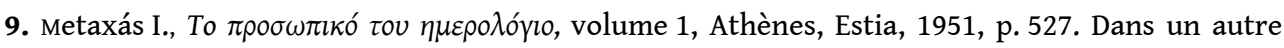
passage de son journal, il écrit: «dans les profondeurs de mon âme, les idées aristocratiques existent toujours ", Ibid., p. 122. 
10. L'expansion territoriale de l'État au XIX ${ }^{e}$ siècle s'accompagne d'une suppression des anciens titres nobiliaires, à l'exception de ceux de la famille royale.

11. vakitiotis P., Popular Autocracy in Greece 1936-1941. A Political Biography of General I. Metaxas, London, Franck Cass, 1998, pp. 25-28.

12. Joakeim I., I. Metaxas. The Formative Years 1871-1922, Mannheim, Bibliopolis, 2000, pp. 16-18.

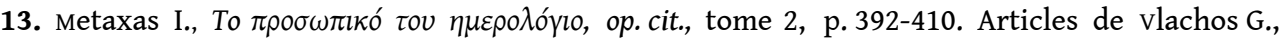

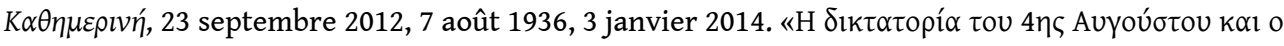

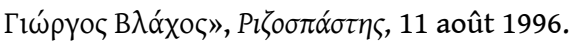

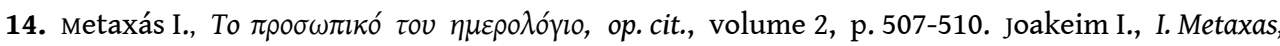

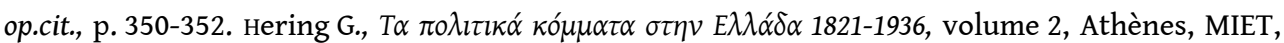
2006, p. 1110-1111.

15. En 1928, le Parti des libres- penseurs totalise 5,30\% des voix; en 1929, 2,73\% des voix ; en 1932, 1,59 \% des voix ; en 1933, 1,60 \% ; en 1936, 3,9 \% des voix.

16. Sa montée au pouvoir sera également favorisée par la mort de 6 hommes politiques de premier plan en 1936: Eleftherios Venizelos, Giorgos Kondylis, Konstantinos Dermertzis, Panayotis Tsaldaris, Pavlos Koundoriotis, Alexandros Zaïmis.

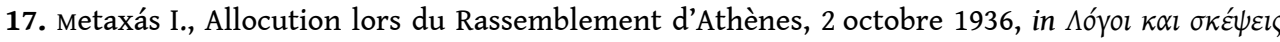
1936-1941, Athènes, Ikaros, 1969, tome 1, p. 44-52.

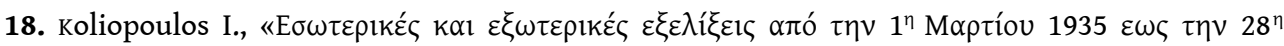

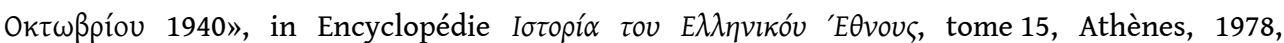

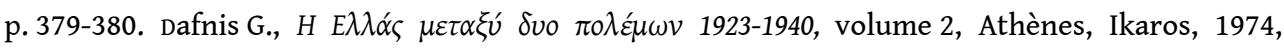

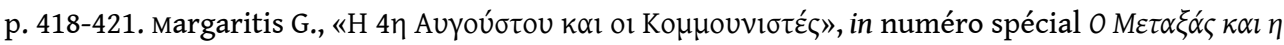

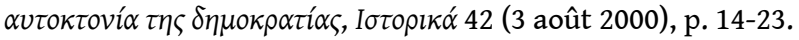

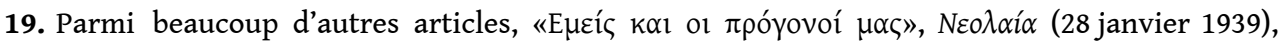
p. 536.

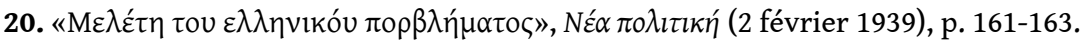

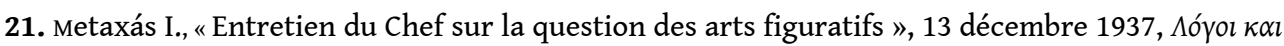

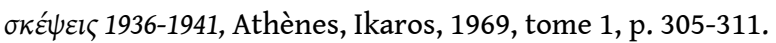

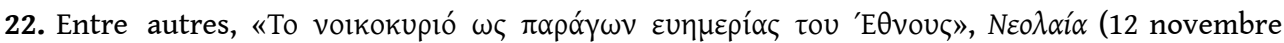
1938), p. 165-166.

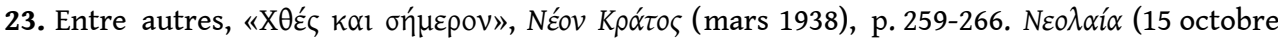

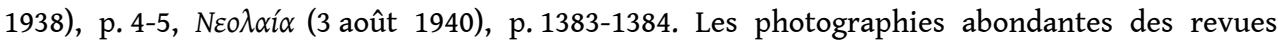
officielles présentent Metaxás comme un héros, qui apparaît aux côtés des soldats, des forces de

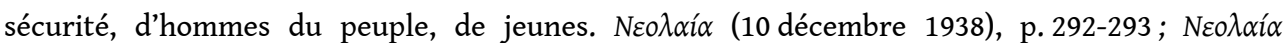
(11 février 1939), p. 601, (24 février 1940), p. 658. Le 2 novembre 1940, le numéro de Neo $\lambda \alpha i ́ \alpha$ est entièrement dédié à Metaxás qui figure en couverture.

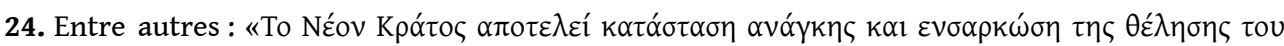

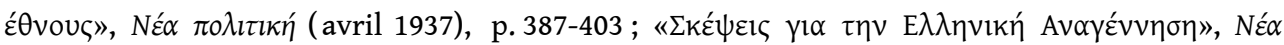

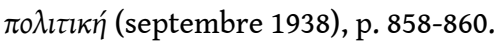

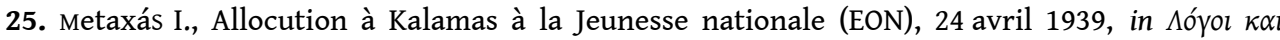

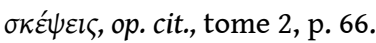

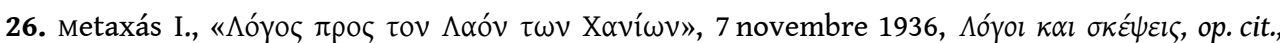
tome 1, p. 101-102.

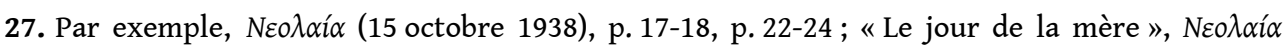

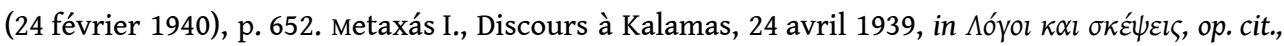
tome 2, p. 56-58. 


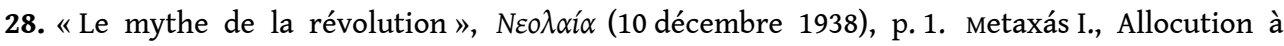

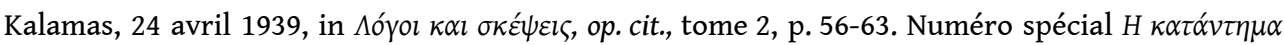
$\tau o v \mu \pi \circ \lambda \sigma \varepsilon \beta l \sigma \mu o v$ (Où mène le bolchévisme), Athènes, éditions de l'EON, 1939.

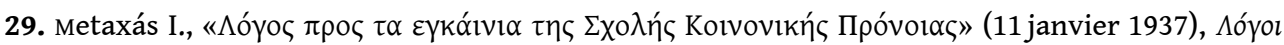

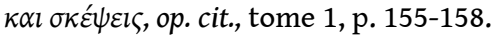

30. Metaxás I., Discours devant l'Union des travailleurs du Pirée, $1^{\mathrm{er}}$ mai 1938, in $\Lambda o ́ \gamma o l ~ \kappa \alpha l ~ \sigma k \varepsilon ́ \psi \varepsilon l \varsigma$, op. cit., tome 1, p. 91-101. Discours au dîner des organisations ouvrières à Neo Faliro, 10 janvier 1937, Ibid., tome 1, p. 152-154.

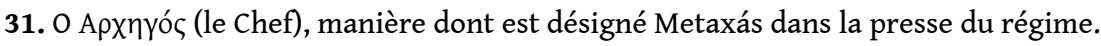

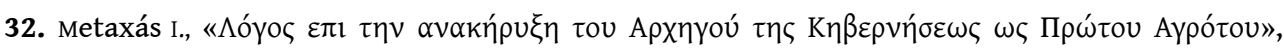

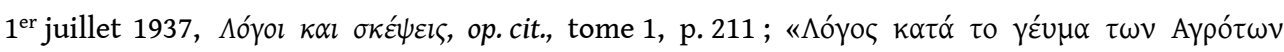

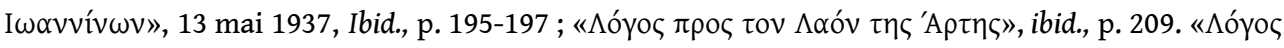

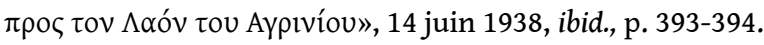

33. L'agriculture est soutenue de 1936 à 1940, la production industrielle s'accroît fortement, les dépenses d'armement représentent une part majeure du budget de l'État. Metaxás I.,

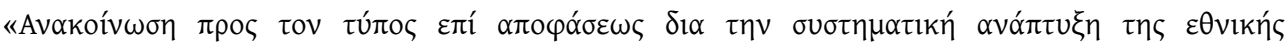

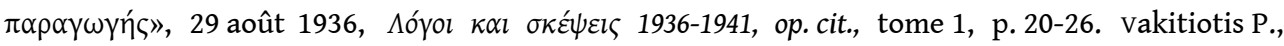

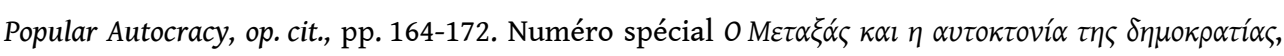

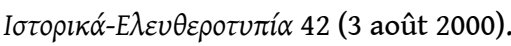

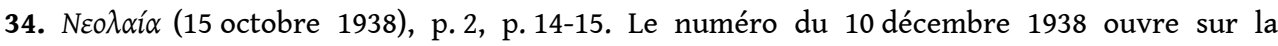
photographie d'un jeune homme travaillant vigoureusement la terre avec une pioche et une

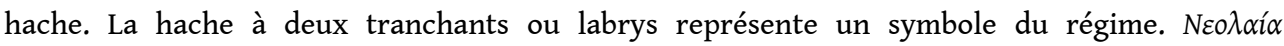
(31 décembre 1938), p. 413-414.

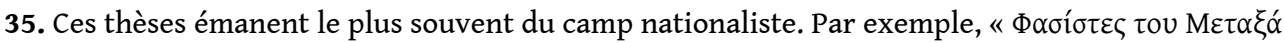

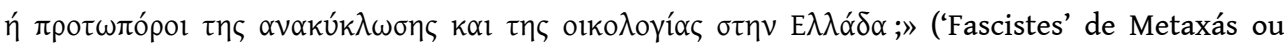

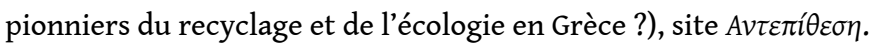

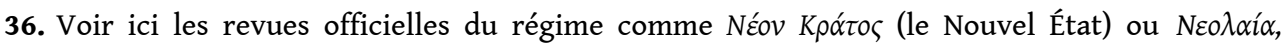
« revue officielle de formation spirituelle, religieuse et nationale de l'Organisation nationale de la

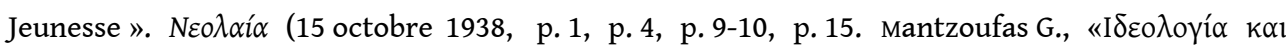

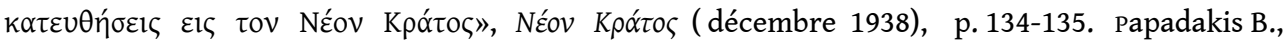

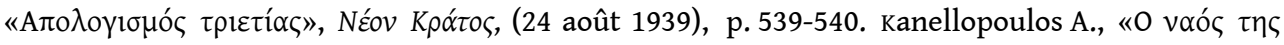

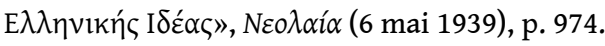

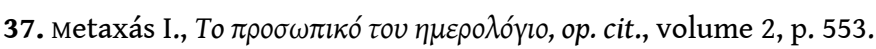

38. Ibid, volume 1, p. 395, volume 2, p. 35, p. 39.

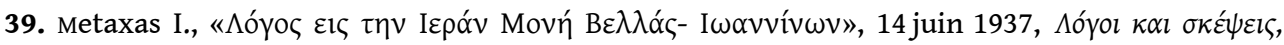
op. cit., tome 1, p. 203-204.

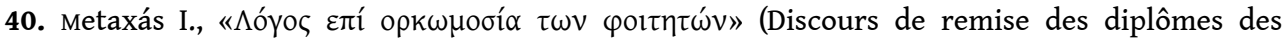

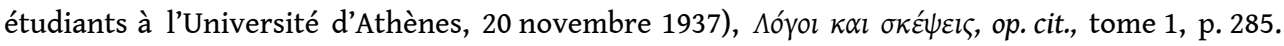

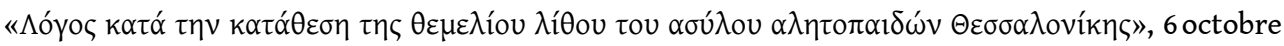
1937, ibid., p. 244-245. Allocution à l'Organisation nationale de la Jeunesse (EON), 29 décembre

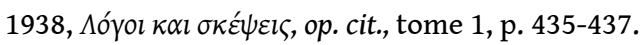

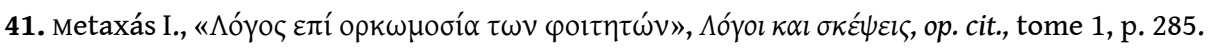

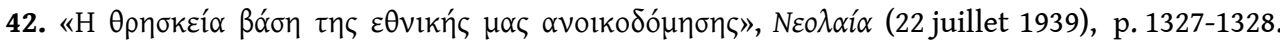

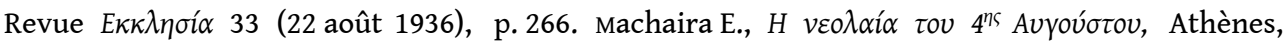
Istoriko Archeio Ellinikis Neolaias, 1987, p. 51-59.

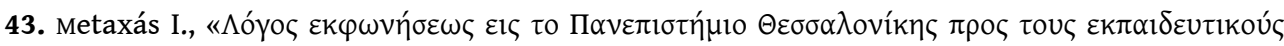

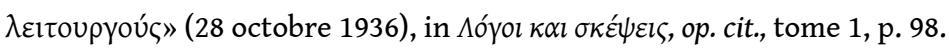




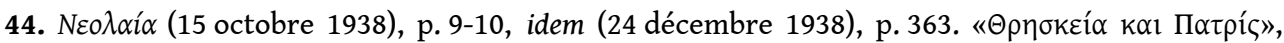

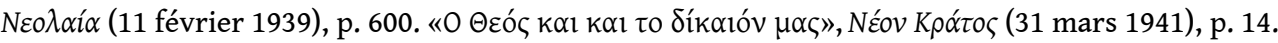
Parmi les auteurs récurrents de ces organes officiels, il faut citer deux intellectuels proches du Chef, Georges Mantzoufas et Nikolaos Koumaros, qui exaltent la thèse de l'État nouveau et le christianisme orthodoxe.

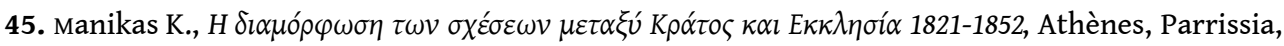
2008. Dépret I., Église orthodoxe et histoire en Grèce contemporaine, Paris, l'Harmattan, 2009, p. 38-46 et p. 117-182.

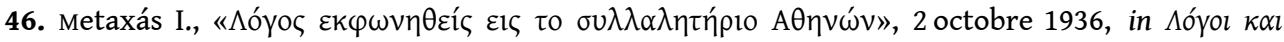

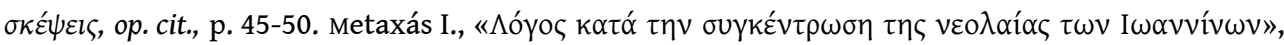

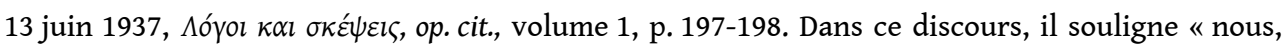
nous avons une profonde foi » et recommande aux jeunes « de contempler les œuvres de (leurs) grands ancêtres à travers (leur) foi chrétienne ».

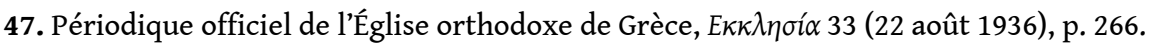

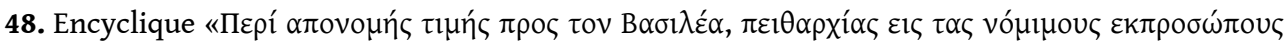

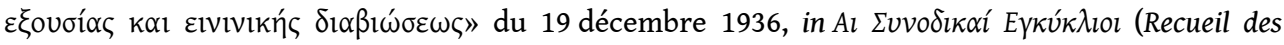
Encycliques du Saint-Synode), tome 2, Athènes, Apostoliki Diakonia, 1956.

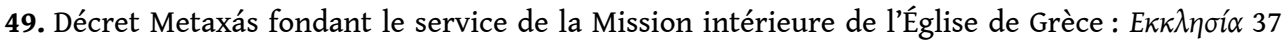
(19 septembre 1936), p. 292.

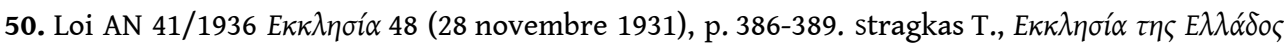

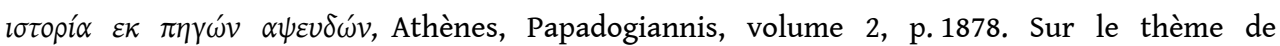
«l'intolérance religieuse » dans l'Église de Grèce dans l'entre-deux-guerres: Anastassiadis T., «Dieu vomit les tièdes! Modernisation ecclésiastique et intolérance religieuse : contribution sur la reconsidération des relations État-Église en Grèce dans l'entre-deux-guerres ", in Grivaud G., petmezas S. (dir.), Byzantina-Moderna: Mélanges en l'honneur d'Hélène Antoniadis-Bibicou, Athènes, Alexandreia, 2007, p. 449-466.

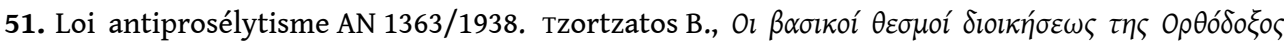

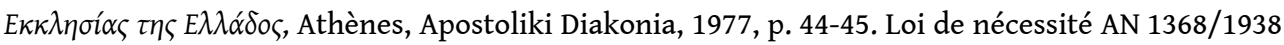

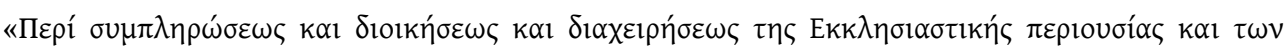

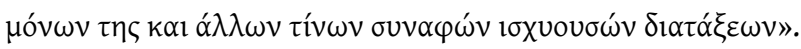

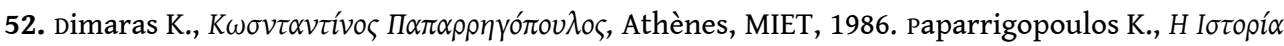

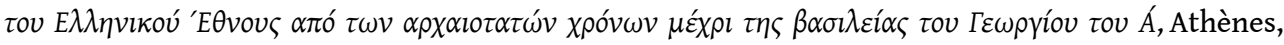
Eleftheroudaki, 1925. Koubourlis I., La formation de l'histoire nationale grecque: l'apport de Spyridon Zambelios (1815-1881), Athènes, EIE-KNE, 2005.

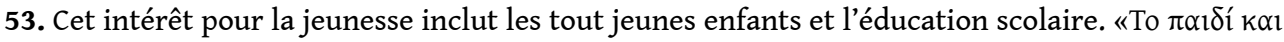

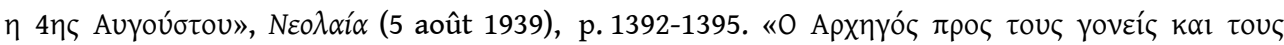

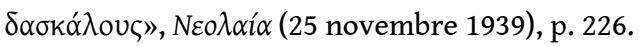

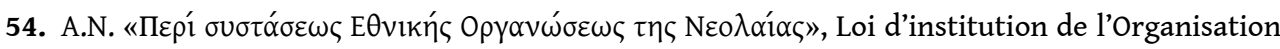
nationale de la Jeunesse (EON), Journal du Gouvernement A, $\mathrm{n}^{\circ} 499$ (10 novembre 1936),

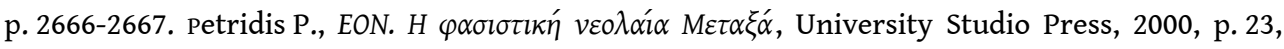
p. 236-244, p. 311-315.

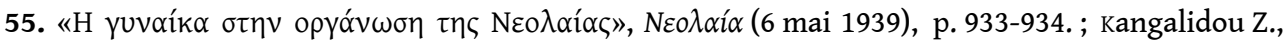

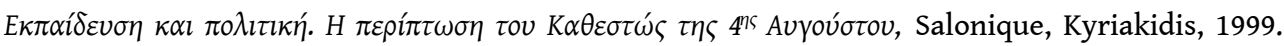

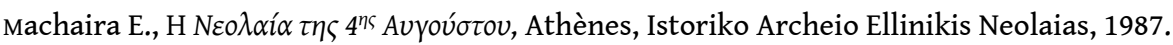

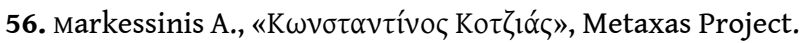

57. Charte de l'EON, in Petridis P., EON., op. cit., p. 33.

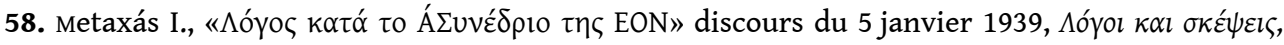
volume 2, 1939, op. cit., p. 8-17, spécialement p. 10. 
59. Ibid., p. 10.

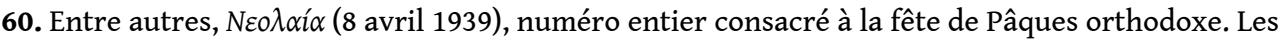
iconographies (symboles, icônes) et textes directement corrélés à l'orthodoxie sont récurrents dans cette revue. Plusieurs publications des EON sont consacrées à la «religion", tel le numéro 50 (1940) des éditions de l'Organisation, adressé aux enseignants.

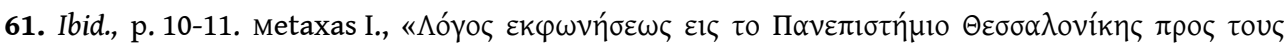

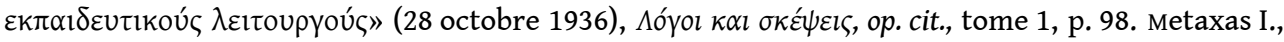

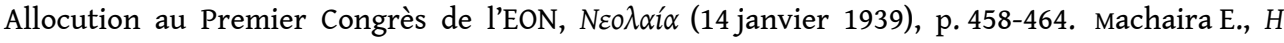

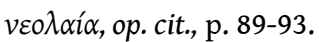

62. Voir le numéro 4 des publications de l'EON, intitulé $T \alpha i \delta \varepsilon \omega \delta \delta \eta \tau \eta \varsigma \varphi v \lambda \eta ́ \varsigma \omega \varsigma \gamma v \omega ́ \mu \omega \nu \tau \eta \varsigma$ $E \lambda \lambda \eta v i k \eta ́ \varsigma \zeta \omega \eta ́ \varsigma$ (Les idéaux de la race comme étalon de la vie hellénique), Athènes, éditions de l'EON, 1939.

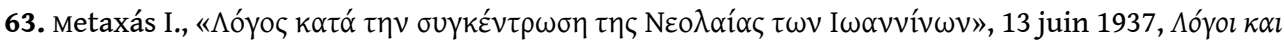

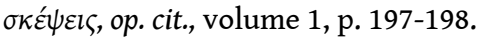

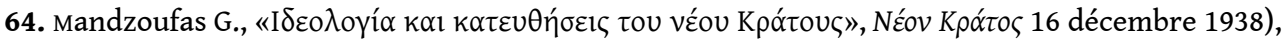
p. 4 , p. 134 .

65. Ibid., p. 7.

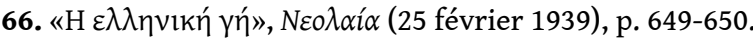

67. Mavrogordatos G., Stillborn Republic. Social Coalitions and Party Strategies in Greece 1922-1936, Berkeley, California University Press, 1983, p. 227. Le recensement de 1928 dénombre 86506 «Turcs», 16755 Pomaques, 81844 Slavo-Macédoniens, 18598 musulmans albanophones/ Tchams, 19679 Koutsovalaques et 27747 Grecs catholiques romains.

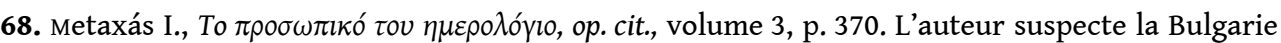
de visées irrédentistes et s'inquiète du risque de cession à ce pays de la Thrace occidentale.

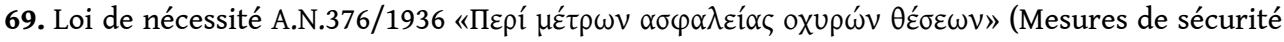
relatives aux places fortifiées), $\Phi E K$ 546. Les deux discours prononcés le 7 octobre 1936 à Komotini (Thrace occidentale) ne mentionnent pas l'élément musulman, qui représente pourtant plus de la moitié de la population de cette ville, afforcer de consolider l'unité nationale:

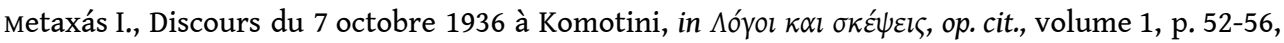

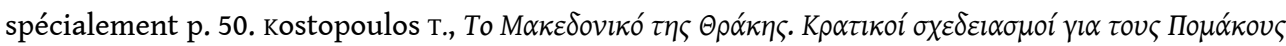
1956-2008, Athènes, Bibliorama, 2009. Markou K., « Les Pomaques de Thrace grecque et leurs choix

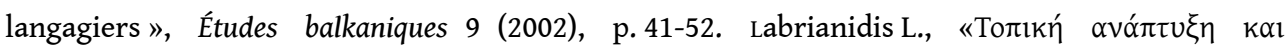

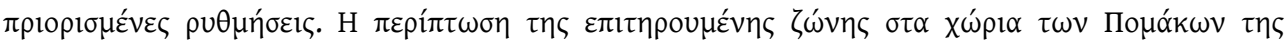

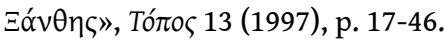

70. L'historien Iakovos Michailidis estime à environ 160000 le nombre de slavophones en

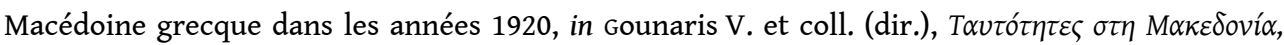
Athènes, Papazisis, 1997, p. 125. Kostopoulos T., $H \alpha \pi \alpha \gamma o \rho \varepsilon v \mu \varepsilon ́ v \eta ~ \gamma \lambda \omega \sigma \sigma \sigma \alpha$, Athènes, Mavri lista, 2000, p. 23-33, p. 222-224.

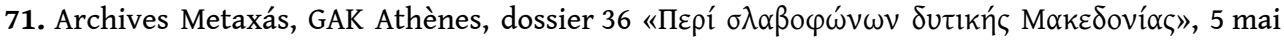
1936-26 avril 1938. Rapports de l'inspecteur des écoles de Macédoine et instituteur Y. Papadopoulos. Ce dernier informe le ministère des progrès réalisés dans l'effort d'hellénisation des zones slavophones de la région.

72. Archives Metaxás, GAK Athènes, 1938, dossier 36, document 2.

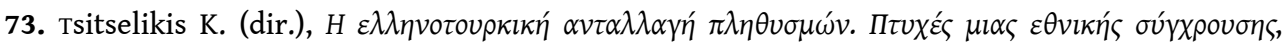
Athènes, KEMO-Kritiki, 2006. LADAS S., The Exchange of Minorities, Bulgaria, Greece and Turkey, New York, Mc Millan, 1932, chapitre 1.

74. Entre autres, $Z \omega \eta ́$ 1048 (5 juillet 1932), p. 212. Une figure influente de l'association est alors Panagiotis Bratsiotis, professeur de théologie à l'Université d'Athènes. 


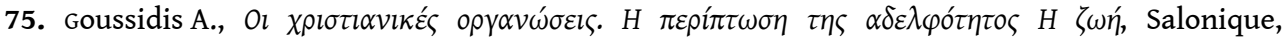

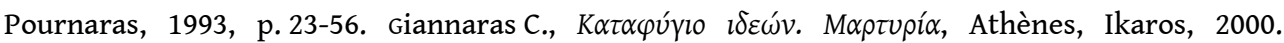
Psilopoulos E., La confrérie de théologiens Zoï, un mouvement spirituel en Grèce, Thèse de $3^{\mathrm{e}}$ cycle,

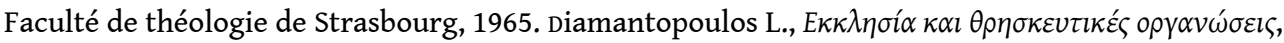

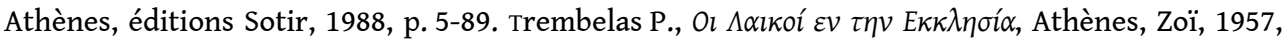

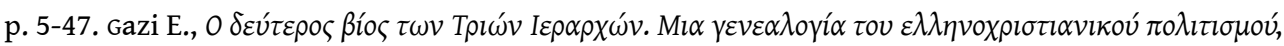
Athènes, Nefeli, 2004.

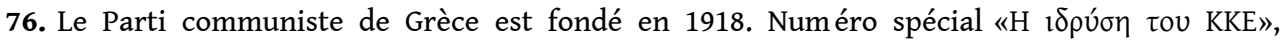

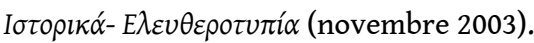

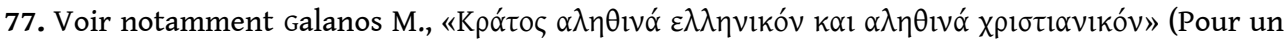
État véritablement grec et véritablement chrétien), Aváđ $\lambda \alpha \sigma \eta 17$ (5 octobre 1936), p. 349-350. La

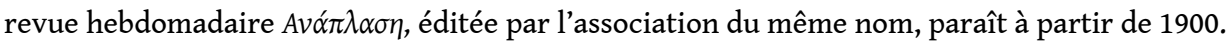

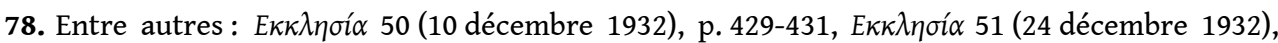

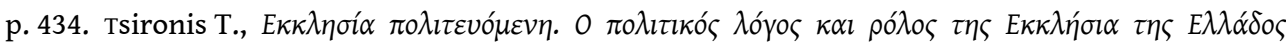
1913-1941, Athènes, Epikentro, 2010, p. 342.

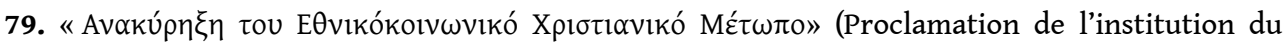

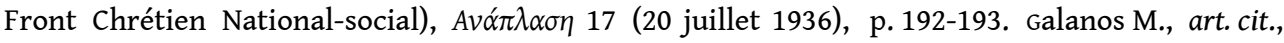
Avá $\lambda \lambda \alpha \sigma \eta 17$ (5 octobre 1936), p. 349.

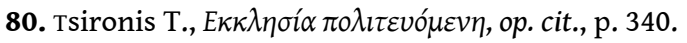

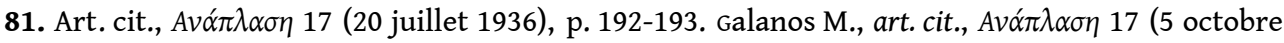
1936), p. 349.

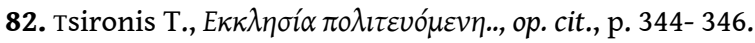

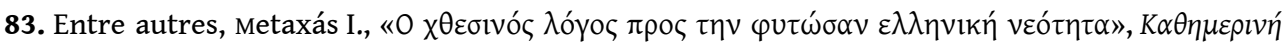
5342 (11 décembre 1936), p. 1-2.

84. Houmourzios S., No Ordinary Crown. A Biography of King Paul of the Hellenes, Londres, Weidenfield et Nicolson, 1972, pp. 81-84. Le scoutisme, créé en 1907 par Lord Robert Baden Powell, général britannique alors à la retraite, est devenu un mouvement international. L'organisation a pour objectif « d'aider les jeunes à (...) construire leur personnalité, en favorisant leur développement physique, mental et spirituel ».

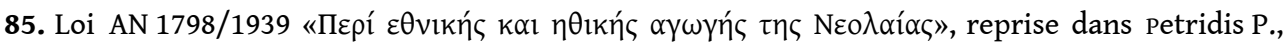

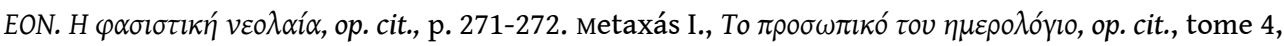

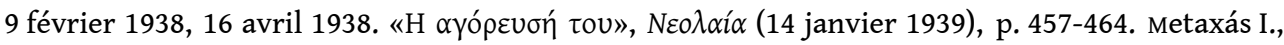

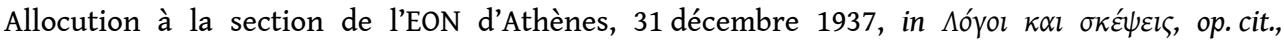

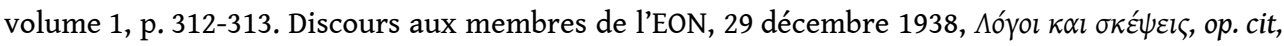
volume 1, p. 435-437.

86. Metaxás I., "Discours de reprise en charge du ministère de l'Éducation nationale et des

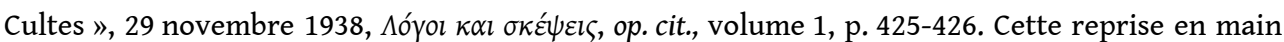
du ministère suit la démission forcée du ministre de l'Éducation, Konstantinos Georgakopoulos, suspecté de dissidence et d'intrigues.

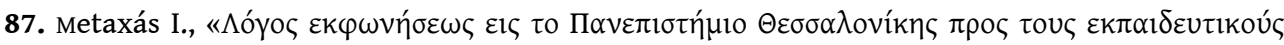

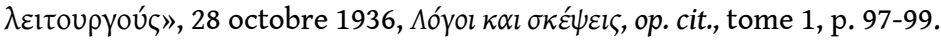

88. metaxás I., "Discours de reprise en charge du ministère de l'Éducation nationale ", 29 novembre 1938, op. cit., volume 1, p. 426.

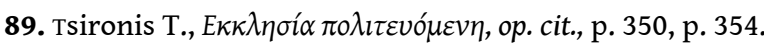

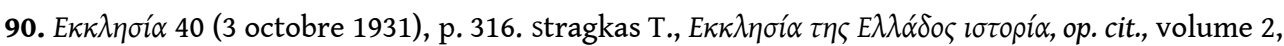
p. 1880.

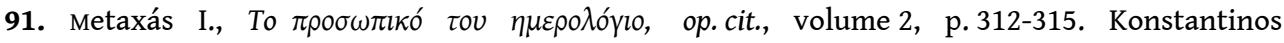
Georgakopoulos, Giorgos Spyridon, Konstantinos Kotzias auraient soutenu l'évêque de Corinthe 
Damaskinos ; d'autres soutiennent l'évêque de Trébizonde Chrysanthos, comme le ministre de la Sécurité, Konstantinos Maniadakis ou le ministre de la Presse, Théologos Nikoloudis.

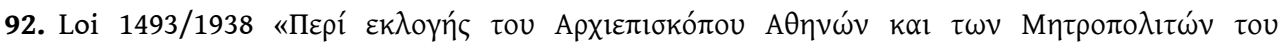

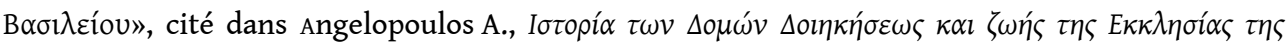

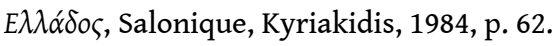

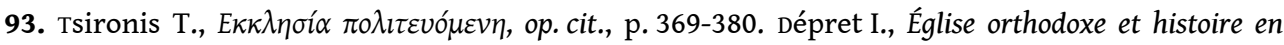
Grèce contemporaine. Versions officielles et controverses historiographiques, Paris, L'Harmattan, 2009, p. 93-99.

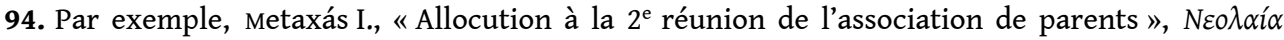

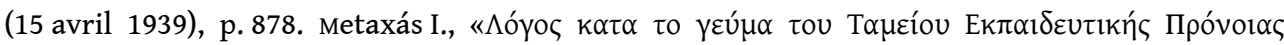

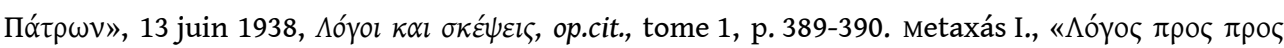

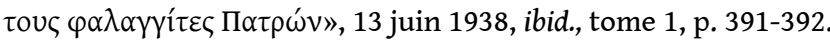

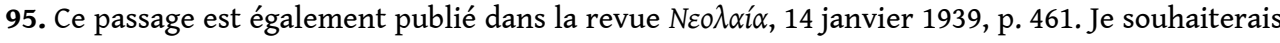
remercier l'historien Christophe Chalas qui a attiré mon attention sur cet extrait.

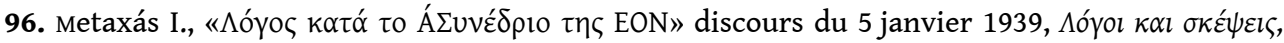
volume 2, 1939, op. cit., p. 8-17, spécialement p. 10.

97. Lagos K., The Metaxas Dictatorship and the Greek Jewry, Thèse de doctorat, Oxford University, 2005, p. 160. Petridis P., EON, op. cit., p. 34, p. 83-84.

98. Ibid., p. 83-84.

99. L'État metaxiste a soutenu l'Église orthodoxe de Grèce dans son combat contre les groupes religieux qualifiés d'«hérésies" (courants chrétiens hétérodoxes, Témoins de Jéhovah,

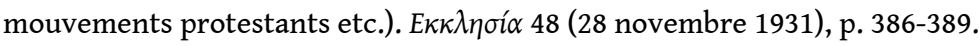

100. Friedländer S., L'Allemagne nazie et les juifs 1933-1939, Paris, Seuil, 2008.

101. Matard-Bonucci A.-M., L'Italie fasciste et la persécution des juifs, Paris, Perrin, 2007.

102. Pierron B., Juifs et chrétiens de la Grèce moderne. Histoire des relations intercommunautaires de 1821 à 1945, Paris, L'Harmattan, 1996. Brustein W., Roots of Hate. Antisemitism in Europe Before the Holocaust, Cambridge, Cambridge University Press, 2003, pp. 46-47.

103. Mazower M., Salonika, City of Ghosts, Londres, Harper Collins, 2004, p. 413. Kallis A., "The Jewish Community of Salonica Under Siege. The Antisemitic Violence of the Summer 1931", Holocaust and Genocide Studies 20 (2006), p. 40.

104. Sur les émeutes anti-juives de 1934 en Thrace turque, Aktar A., "1934 Trakya olaylari ve Türk Milliyetçiliği”, Tarih ve Toplum 155 (1996), p. 45-56 ; HÜR A., “1934 Trakya olaylari”, Taraf (10 juillet 2010). özkirimli U., sofos S., Tormented by History. Nationalism in Greece and in Turkey, New York, Columbia University Press, 2008, p. 168.

105. Kallis A., "The Jewish Community", art. cit., p. 34-56.

106. En 1941, le nombre des juifs en Grèce est estimé à environ 79950 personnes. Molho R., «La politique de l'Allemagne contre les juifs de Grèce. L'extermination de la communauté juive de Salonique 1941-1944 », Revue d'histoire de la Shoah 185 (2006), p. 375.

107. vidal-sephiha H., "La langue judéo-espagnole en Europe ", in veinstein G. (dir.), Salonique 1850-1918 et le réveil des Balkans, Paris, Autrement, 1992, p. 79-95.

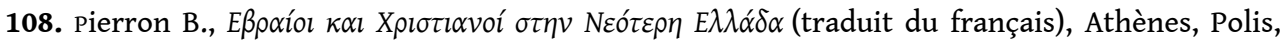
2004, p. 243-257. Molho R., in veinstein G. (dir.), Salonique 1850-1918, op.cit., p. 68-78.

109. Tsitselikis K., Old and New Islam in Greece, Leiden, Martinus Nijhof, 2012, p. 215. Mavrogordatos G., Stillborn Republic, op. cit., p. 256.

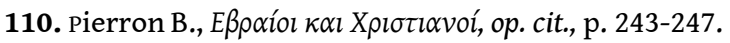

111. Ibid. Lagos K., The Metaxas Dictatorship and Greek Jewry, Thèse de doctorat, Université d'Oxford, 2005, p. 153. 
112. Molho R., «La politique de l'Allemagne contre les juifs de Grèce. L'extermination de la communauté juive de Salonique 1941-1944 », Revue d'histoire de la Shoah 185 (2006), p. 365-378.

113. Ibid.

114. Archives Metaxás, GAK (Archives de l'État) d'Athènes, dossier 28, p. 3-4.

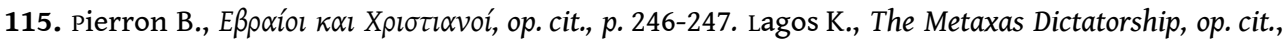
p. 151.

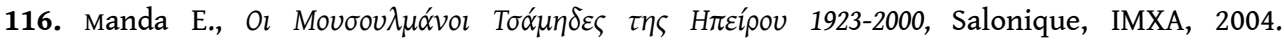

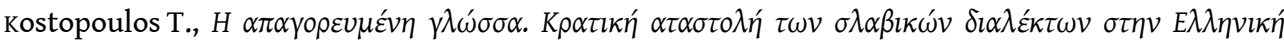

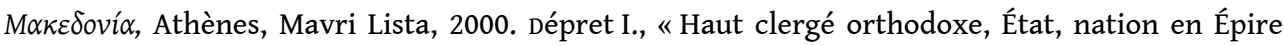
grecque (1912-1939) », Revue d'Histoire Moderne et Contemporaine 56 (2009), p. 123-149.

117. Anastassiadou M., Salonique 1830-1912, une ville ottomane à l'ère des réformes, Leyden, Brill, p. 431-432.

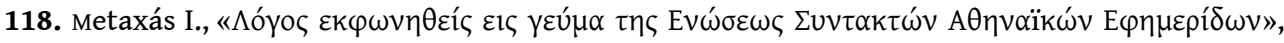

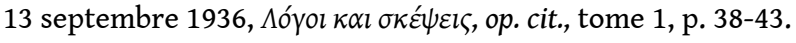

119. "Greece Curbs News of Actions in Reich", The New York Times, 26 novembre 1938, "Greece and Britain. Dictator Talks to Sunday Times", The London Times, 11 juillet 1937.

120. Appel du ministre de la région Macédoine P. Dragoumis aux éditeurs de presse juifs,

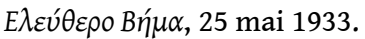

121. Lagos K., The Metaxas Dictatorship, op. cit., pp. 170-173, pp. 184-185.

122. "Nazi propaganda in Greece”, The Manchester Guardian, 5 mai 1937.

123. Ibid., p. 176.

124. Molho R., «Les Juifs en Grèce au $\mathrm{xx}^{\mathrm{e}}$ siècle ", Matériaux pour l'histoire du temps présent 71 (2006), p. 46-47.

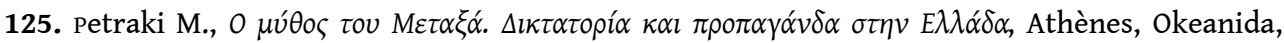
2006.

126. vatikiotis P., Popular Autocracy, op. cit., p. 171.

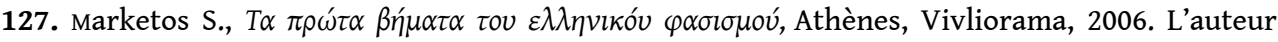
s'inspire de l'approche de Robert Paxton, The Anatomy of Fascism, Londres, Allen Lane, 2004.

128. weber E., Varieties of Fascisms, Princeton, Van Nostrand, 1964.

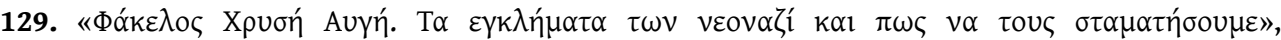

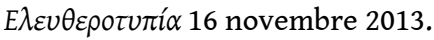

\section{ABSTRACTS}

The Ioannis Metaxas' regime, from August 1936 to January 1941, is most often brought closer to the authoritarian and paternalistic model of Salazar's Portugal-or Franco's Spain-than to fascism or nazism stricly speaking. This article focuses on a critical aspect of the "4th August Regime": its relationships with religion. The enhancement of christianism by the political authority, which is an often noticed point, does not in fact represent a real discontinuity with respect to earlier administrations. The religious tolerance of the governement, its peculiar management of religious minorities-in the European context of the late 1930s-are examined in all their ambiguities. The look taken at this 20th century's regime crystallizes still current debates and historiographical tensions in Greece, all the more sensitive as they meet the issue of the State and Greek population's attitude faced with the Shoah. 
Le gouvernement Metaxás, au pouvoir d'août 1936 à janvier 1941 en Grèce, est le plus souvent rapproché du modèle autoritaire et paternaliste du Portugal salazariste - ou de l'Espagne franquiste - plus, à strictement parler, que du fascisme et du nazisme. Cet article se centre sur un aspect critique de la «Grèce du 4 août » : ses rapports au religieux. La valorisation insistante du christianisme par le régime, une dimension souvent pointée, ne marque finalement pas une rupture au regard des expériences politiques précédentes. La question de la tolérance religieuse de ce gouvernement, sa gestion particulière des minorités religieuses dans le contexte européen de la fin des années 1930 sont examinée, dans toutes leurs ambiguïés. Le regard porté, en Grèce, sur ce régime passé cristallise des débats toujours actuels et des tensions historiographiques d'autant plus sensibles qu'elles rejoignent la question de l'attitude de l'État et de la population helléniques face à la Shoah.

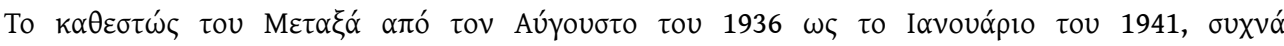

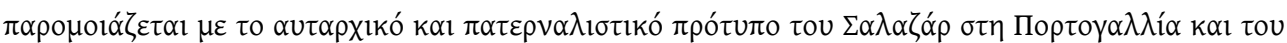

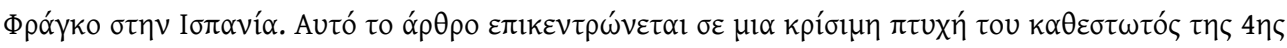

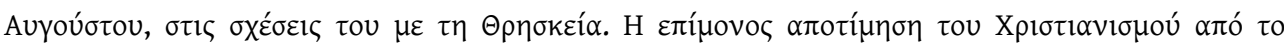

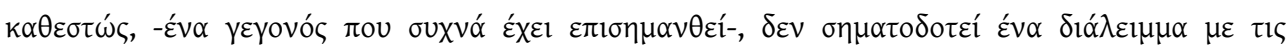

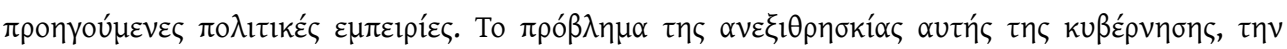

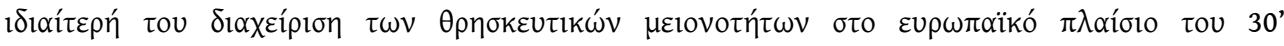

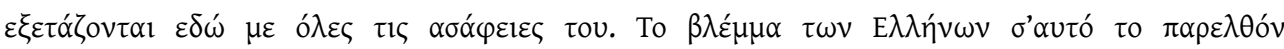

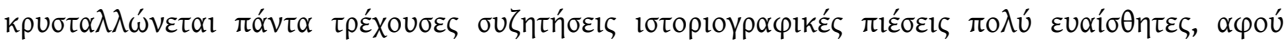

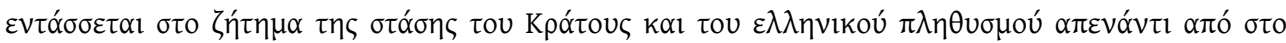

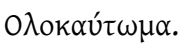

\section{INDEX}

\section{Geographical index: Grèce}

Keywords: Metaxas Ioannis (1871-1941), Indoctrination, Fascism, Politics and religion, EON, Slavo-Macedonian, Greece, Interwar period (1918-39), History

Mots-clés: Metaxás Ioannis (1871-1941), Metaxás Ioannis (1871-1941), endoctrinement, fascisme, politique et religion, EON, Slavomacédoniens

motsclesmk МЕТАКСАС ЈОАНИС (1871-1941), ИНДОКТРИНАЦИЈА, ФАШИЗМОТ, ПОЛИТИКАТА И РЕЛИГИЈАТА, ЕОN, СЛАВОМАКЕДОНСКО, ГРЦИЈА, МЕЃУВОЕНИОТ, ИСТОРИЈА

motsclestr Metaksas Yannis (1871-1941), Doktrinleştirme, Faşizm, Siyaset ve din, EON, SlavoMakedonya, Yunanistan, Savaşlar arası (1919-39), Tarih

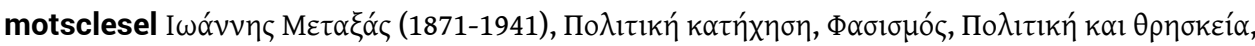

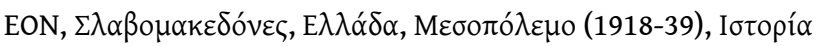

Subjects: Histoire

Chronological index: entre-deux-guerres (1918-1939)

\section{AUTHOR}

\section{ISABELLE DÉPRET}

Chargée d'enseignement

Université de sciences politiques - Beykoz -- Istanbul 